\title{
Aerosol-Cloud Interaction in Deep Convective Clouds over the Indian Peninsula Using Spectral (Bin) Microphysics $\mathscr{D}$
}

\author{
K. GAYATRI AND S. PATADE \\ Indian Institute of Tropical Meteorology, and Department of Atmospheric and Space Science, \\ Savitribai Phule Pune University, Pune, India \\ T. V. PRABHA \\ Indian Institute of Tropical Meteorology, Pune, India
}

(Manuscript received 9 February 2017, in final form 4 July 2017)

\begin{abstract}
The Weather Research and Forecasting (WRF) Model coupled with a spectral bin microphysics (SBM) scheme is used to investigate aerosol effects on cloud microphysics and precipitation over the Indian peninsular region. The main emphasis of the study is in comparing simulated cloud microphysical structure with in situ aircraft observations from the Cloud Aerosol Interaction and Precipitation Enhancement Experiment (CAIPEEX). Aerosol-cloud interaction over the rain-shadow region is investigated with observed and simulated size distribution spectra of cloud droplets and ice particles in monsoon clouds. It is shown that size distributions as well as other microphysical characteristics obtained from simulations such as liquid water content, cloud droplet effective radius, cloud droplet number concentration, and thermodynamic parameters are in good agreement with the observations. It is seen that in clouds with high cloud condensation nuclei $(\mathrm{CCN})$ concentrations, snow and graupel size distribution spectra were broader compared to clouds with low concentrations of $\mathrm{CCN}$, mainly because of enhanced riming in the presence of a large number of droplets with a diameter of $10-30 \mu \mathrm{m}$. The Hallett-Mossop ice multiplication process is illustrated to have an impact on snow and graupel mass. The changes in $\mathrm{CCN}$ concentrations have a strong effect on cloud properties over the domain, amounts of cloud water, and the glaciation of the clouds, but the effects on surface precipitation are small when averaged over a large area. Overall enhancement of cold-phase cloud processes in the high$\mathrm{CCN}$ case contributed to slight enhancement $(5 \%)$ in domain-averaged surface precipitation.
\end{abstract}

\section{Introduction}

Deep convective cloud (DCC) systems are prominent features of the tropical atmosphere that have an important role at a spectrum of space and time scales from local diurnal cycles to the planetary scale (Zelinka and Hartmann 2009; Liu 2011). Over India, large areas of deep convection are found with high cloud tops (Balachandran and Rajeevan 2007). The vertical structure of these clouds shows a well-defined mixed-phase region in reanalysis and satellite datasets (Urankar et al.

Supplemental information related to this paper is available at the Journals Online website: http://dx.doi.org/10.1175/JAS-D-170034.s1.

Corresponding author: Kulkarni Gayatri, gayatri@tropmet.res.in; T. V.Prabha, thara@tropmet.res.in
2012; Abhik et al. 2013; Kumar et al. 2014; Rajeevan et al. 2013; Ravi Kiran et al. 2015), in situ aircraft observations (Prabha et al. 2011; Patade et al. 2015, 2016), and numerical simulations (e.g., Hazra et al. 2013a; Patade et al. 2016). Indirect effects where aerosol particles act as cloud condensation nuclei $(\mathrm{CCN})$ are widely studied. However, the response of mixed-phase clouds to aerosol loading is not well understood (Storer and van den Heever 2013). Aerosol effects on deep convective clouds and precipitation are difficult to determine because of the coupling between microphysics and dynamics (Tao et al. 2012; Altaratz et al. 2014; Fan et al. 2016). Several observational and modeling studies support the hypothesis that higher aerosol loading leads to the invigoration of DCC [see, e.g., Andreae et al. (2004), Khain et al. (2005), Rosenfeld et al. (2008), Fan et al. (2013), Storer et al. (2014), an extensive review article by Altaratz et al. (2014) and references therein, 
Sheffield et al. (2015), and an updated review by Fan et al. (2016)]. However, many numerical studies have shown that an increase in aerosol concentrations inhibit or enhance convection depending upon the environmental conditions such as atmospheric humidity, instability, and vertical wind shear (e.g., Rosenfeld 1999; Seifert and Beheng 2006; Tao et al. 2007; Khain et al. 2008, 2009; Storer et al. 2010; Xue et al. 2012; Storer and van den Heever 2013).

The investigation of heavy precipitation events over India drew great interest since the findings of Goswami et al. (2006), where they found a significant increase in the frequency and magnitude of extreme rain events (and a decreasing trend in moderate rain events) over the Indian monsoon region during the last 50 years (1951-2000). Sengupta et al. (2013) used satellite data and found that large aerosol loading within the core monsoon region might have facilitated the invigoration of monsoon clouds by suppressing warm rain. Hazra et al. (2013b), using a mesoscale model with bulk microphysical scheme, illustrated that high concentrations of absorbing aerosols could lead to invigoration of convection, enhancing precipitation and resulting in more active monsoon conditions. Using aircraft and satellite observations and idealized model simulations, Sarangi et al. (2015, 2016) suggested that aerosol-induced cloud invigoration may happen over the Indian region. However, in these simulations, the ideal periodic boundary conditions, different realizations of the flow, and dynamic-thermodynamic feedbacks may influence the robustness of aerosol impacts on clouds. This uncertainty is reduced if the clouds are developed in realistic manner and the domain is large enough to include many clouds so that the feedbacks between cloud processes and large-scale environment are incorporated. Seifert et al. (2012) were first to report such simulations using a systematic 3-yr-long convective-scale weather prediction model over Germany. They concluded that changes in $\mathrm{CCN}$ have a significant effect on the cloud micro- and macrostructure, but the impact on surface precipitation is minimal. Similarly, in short-period realistic simulations of heavy rainfall events, such as Grabowski and Morrison (2016) and Lee and Baik (2016), the differences in domain-averaged surface precipitation were small. Several reported studies on the aerosol effect on precipitation over the Indian region correspond mostly to regional aspects. However, convective clusters embedded in more realistic large-scale conditions over a large area were not investigated.

There are very few studies available over the Indian region on aerosol-cloud interaction that investigate the cloud particle size spectra. Extensive aircraft data over India suggested that the effect of aerosol loading and moisture modulates the drop size distribution, which in turn affects ice microphysical processes, especially the processes in the mixed-phase region (Patade et al. 2015). Khain et al. (2015) have discussed the importance of the accurate description of size distribution of particles in cloud-resolving models. Fan et al. (2013) have stressed that aerosol effects appear through the influence on particle size distributions, and the accurate description of sizes of ice crystals and their fall velocities is a key factor to simulate cloud fraction and cloud thickness. A bin microphysics scheme allows particle distribution spectra to evolve naturally along with in-cloud and large-scale processes, whereas it is predefined in the case of the bulk schemes. Therefore, these complexities and the rain formation processes in deep clouds are most likely not well represented in bulk models. Hence, an explicit approach such as bin microphysics is suitable to perform such investigations [see Khain et al. (2015) for details on the bin and bulk approaches]. In fact, most of the work carried out to investigate the aerosol effect on the monsoon environment has been based on numerical studies using bulk microphysical schemes (Hazra et al. 2013a,b), and detailed studies with bin microphysics are lacking. Thus, more systematic analysis is required to investigate aerosol-cloud interaction in monsoon clouds using bin microphysics, especially with intercomparison of simulated and observed particle size spectra.

We conducted single-day three-dimensional (3D) simulations of clouds growing in a monsoon environment with spectral bin microphysics, with a specific emphasis on comparing particle size distributions and their vertical variation within deep cumulus clouds. The simulations were conducted under different aerosol conditions to investigate cloud-aerosol interactions. The cloud microphysical characteristics and rainfall formation mechanism are investigated. This paper is structured as follows: section 2 covers the data and instrumentation, as well as the model description, details of the selected case, and the design of numerical experiments, results are presented in section 3 , and the summary and conclusions are given in section 4 .

\section{Materials and methods}

\section{a. Data and instrumentation}

To better understand aerosol-cloud interactions, a national experiment, Cloud Aerosol Interaction and Precipitation Enhancement Experiment (CAIPEEX), was conducted over north-central peninsular India using an instrumented research aircraft (Kulkarni et al. 2012) over the rain-shadow area in the Indian Peninsula. The DCC case considered for this study was profiled by an instrumented aircraft between 1500 and 1800 LST 
TABLE 1. List of instruments on board for CAIPEEX with sampling details.

\begin{tabular}{llcc}
\hline \multicolumn{1}{c}{ Variable } & \multicolumn{1}{c}{ Instrument } & Range & Resolution \\
\hline Liquid water content $\left(\mathrm{g} \mathrm{m}^{-3}\right)$ & DMT LWC-100 & $0-3$ & 0.01 \\
Aerosol $(\mu \mathrm{m})$ & DMT PCASP SPP-200 & $0.1-3$ & 0.02 \\
$\mathrm{CCN}(\mu \mathrm{m})$ & DMT CCN counter & $0.5-10(0.1 \%-1.2 \%$ supersaturation $)$ & 0.5 \\
Cloud droplet spectra $(\mu \mathrm{m})$ & DMT FSSP & $2-50$ & $1-2$ \\
Cloud particle spectra $(\mu \mathrm{m})$ & DMT CIP & $25-1550$ & 25 \\
Precipitation particle spectra $(\mu \mathrm{m})$ & DMT PIP & $100-6200$ & $-5-50$ \\
Cloud particle spectra $(\mu \mathrm{m})$ & DMT CAS & -30 to 50 & - \\
$T\left({ }^{\circ} \mathrm{C}\right)$ & Aventech-AIMMS & $0-100$ & 0.01 \\
$\mathrm{RH}(\%)$ & Aventech-AIMMS & 0.1 \\
\hline
\end{tabular}

27 October 2011. The aircraft was equipped with various instruments such as a forward scattering spectrometer probe (FSSP), cloud-imaging probe (CIP), precipitationimaging probe (PIP), passive cavity aerosol spectrometer probe (PCASP SPP-200), hotwire probe [Droplet Measurement Technologies (DMT) liquid water content (LWC)-100], and an Advanced Airborne Measurement Solutions air data probe [Aircraft Integrated Meteorological Measurement System (AIMMS)]. The details about these instruments are given in Table 1. Both CIP and PIP with antishattering tips were used, and the data were processed by the system for optical array probe (OAP) data analysis (SODA) developed by the National Center for Atmospheric Research (NCAR). Details of various corrections applied to CIP-PIP data during CAIPEEX are described in Patade et al. (2015). Large water droplets and ice particles were also measured by a high-volume twodimensional (2D) optical array probe (2DS) probe. All observations were carried out with a $1-\mathrm{Hz}$ sampling rate, and average aircraft speed was about $100 \mathrm{~m} \mathrm{~s}^{-1}$. The CCN number concentration at four different supersaturations $(0.2 \%, 0.4 \%, 0.6 \%$, and $0.8 \%)$ was measured below cloud base using a DMT CCN counter on board the aircraft. The $\mathrm{CCN}$ counter measures $\mathrm{CCN}$ concentrations at a fixed supersaturation for $3 \mathrm{~min}$. The data points with stabilized temperature gradients in the $\mathrm{CCN}$ column are used for finding spectra (Varghese et al. 2016).

\section{b. Model description}

Simulations were performed with the Weather Research and Forecasting (WRF) Model, version 3.6.1, developed at NCAR (Skamarock et al. 2005). The spectral bin microphysics (SBM) scheme coupled with WRF Model is based on the Hebrew University Cloud Model (HUCM) described by Khain et al. (2004). The detailed version of SBM (i.e., the full SBM) has eight size distributions [aerosol, water drops, three types of ice crystals (columns, plates, and dendrites), snow, graupel, and hail]. Since the full SBM is highly computationally expensive when run three- dimensionally and for a large area for longer simulation periods, a fast SBM version (Khain et al. 2009, 2010) was used in this study. Fast SBM uses four size distribution spectra to represent hydrometeors in the model, including water drops (cloud and rain), lowdensity ice (ice and snow), and high-density ice (graupel and hail). While ice crystals (as particles $<150 \mu \mathrm{m})$ and snow particles $(>150-\mu \mathrm{m}$ particles) are calculated on one size distribution as low-density ice, graupel and hail are combined as high-density ice and represented as one size distribution without a separation. In fast SBM, graupel particle formation and growth can occur by collisions between drops and crystals and between drops and snow. Collisions between pristine ice crystals or snow and small water droplets result in graupel if the mass of a water drop is greater than the pristine ice crystal or snow. It is assumed that the riming of ice crystals and snow leads to graupel formation when the mass of rimed water exceeds half of a particle mass. The fastSBM version used in this study does not have graupel-ice crystal and graupel-snow collision processes. A collision between water and a graupel particle increases the mass of the graupel. Aggregation of snow with ice particles lead to graupel formation.

The fast version retains the advantages of full SBM and simulates microphysical-dynamical structure and precipitation similar to the full SBM (Khain et al. 2005). The microphysics is based on solving kinetic equations for size distribution functions for all hydrometeors as well as aerosol particles (APs). Each size distribution is described using 33 doubling-mass bins. The maximum fall velocity of high-density hydrometeors (corresponding to bin 33) is $8 \mathrm{~m} \mathrm{~s}^{-1}$. The $\mathrm{CCN}$ activation spectrum at the initial time step is given by a semiempirical formula:

$$
N_{\text {ccn }}=N_{0} S^{k}
$$

where $S$ is supersaturation (\%) and $N_{0}$ and $k$ are measured constants (Khain et al. 2000). Further details 

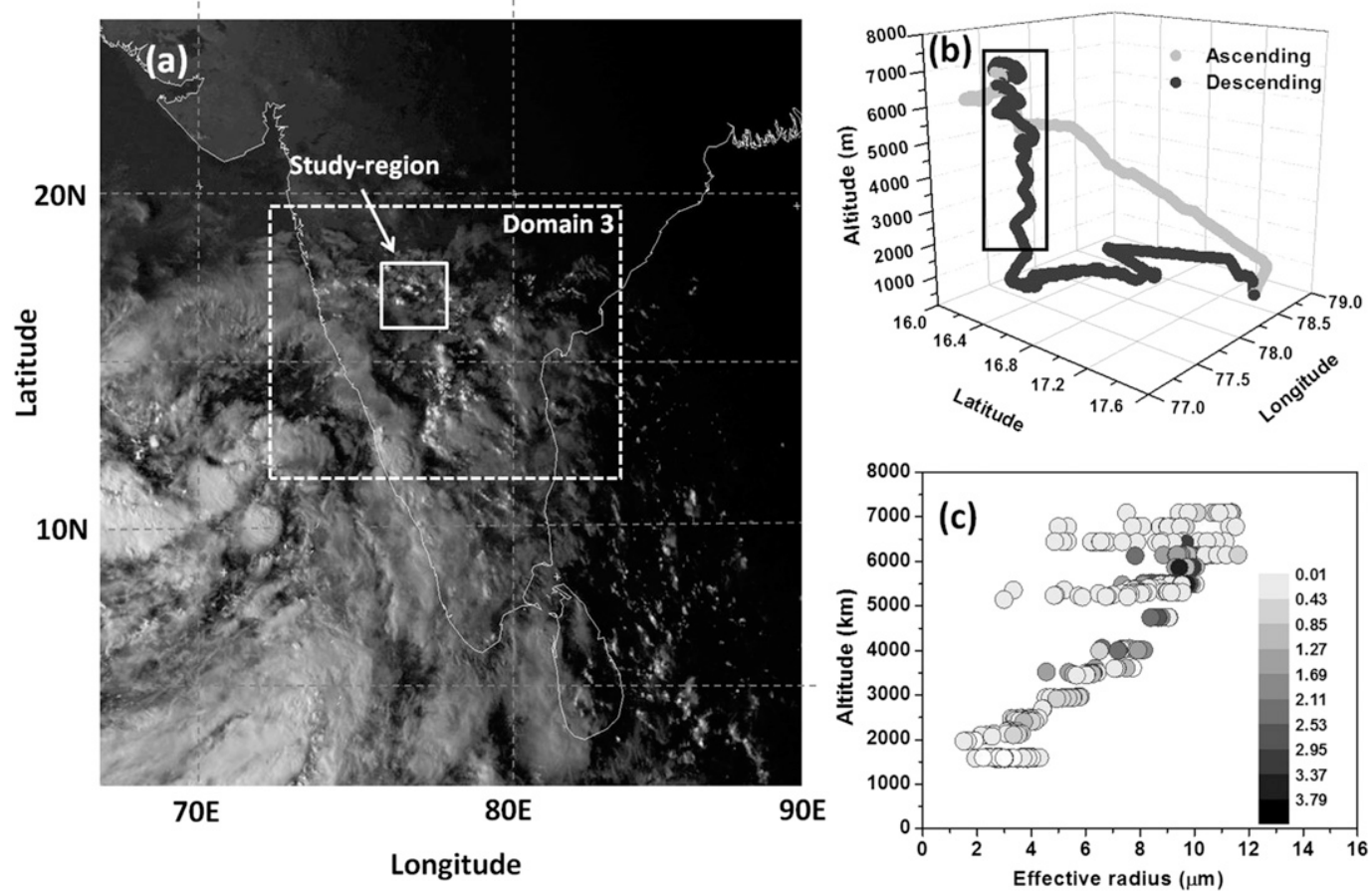

FIG. 1. (a) Satellite image from Meteosat visible channel at 1730 LST. Dashed box denotes the whole domain, and solid box denotes the study region where aircraft observations are also conducted. (b) The 3D flight track over the study region and (c) cloud droplet effective radius ( $\mu \mathrm{m}$; color mapped with LWC) from the aircraft observations over the box shown in flight track vertical profiling the deep convective cloud.

will not be repeated here and can be found in Khain et al. $(2004,2009)$.

\section{c. Case description}

Deep convective clouds were observed on 27 October 2011 over the area of peninsular India referred to as the "study region" (solid white box in Fig. $1 \mathrm{a} ; 15.5^{\circ} \mathrm{N}$, $76.0^{\circ} \mathrm{E} ; 15.5^{\circ} \mathrm{N}, 77.5^{\circ} \mathrm{E} ; 17.0^{\circ} \mathrm{N}, 77.5^{\circ} \mathrm{E}$; and $17.0^{\circ} \mathrm{N}$, $76.0^{\circ} \mathrm{E}$ ), in the leeward side of the Western Ghats around Mahbubnagar, India $\left(16.46^{\circ} \mathrm{N}, 77.56^{\circ} \mathrm{E}\right)$. This region receives $\approx 20 \%$ less rainfall than the windward side of the Western Ghats (Rao 1976) and is termed as the rain-shadow region. Apart from monsoon, this region mainly gets rain during October-December from a retreating monsoon known as the northeast monsoon, during which only the peninsular region of India receives rainfall. The onset of the northeast monsoon was on 24 October (Nair et al. 2015), and several places in the southern peninsula received rainfall. More details about the synoptic and dynamic features about this region are given in Harikishan et al. (2014) and Narkhedkar et al. (2014). Convective clouds were seen in the satellite image with both shallow and deep convection resembling mesoscale convective clusters over coastal areas (Fig. 1a). These systems moved west- northwestward, inland during the diurnal cycle. The deep convective system observed over the study region was profiled by aircraft and monitored by radar. The measured radar reflectivity from a C-band Doppler radar [5.63 GHz, Advanced Radar Corporation (ARC) upgraded WSR-74C] gives some basic idea of the spatial cloud structure at the site (supplementary Fig. S1). The maximum reflectivity observed was approximately $42 \mathrm{~dB} Z$, and a vertical cross section of the radar reflectivity shows echo top at $9 \mathrm{~km}$. The deep convective cloud system lasted for about $2 \mathrm{~h}$ with an area covering about $90 \mathrm{~km}^{2}$, and the maximum vertical integrated liquid was about $7.4 \mathrm{~kg} \mathrm{~m}^{-2}$. Aircraft observations were conducted up to an altitude of $7.5 \mathrm{~km}$, and the corresponding three-dimensional flight track is shown in Fig. 1b. Cloud observations in the form of cloud passes at each height over the deep convective cloud (shown with a box in Fig. 1b) during descent from $7.5 \mathrm{~km}$ to the cloud base is used in the detailed intercomparison. Aircraft observations correspond to the developing stage of the convective cloud, and only a small part of the flight was in the top stratiform region. The vertical variation in effective radius, color mapped with cloud liquid water $\left(\mathrm{g} \mathrm{m}^{-3}\right)$, showed (Fig. 1c) that at each level, there is a large variation in the effective radius and liquid water, which can be 

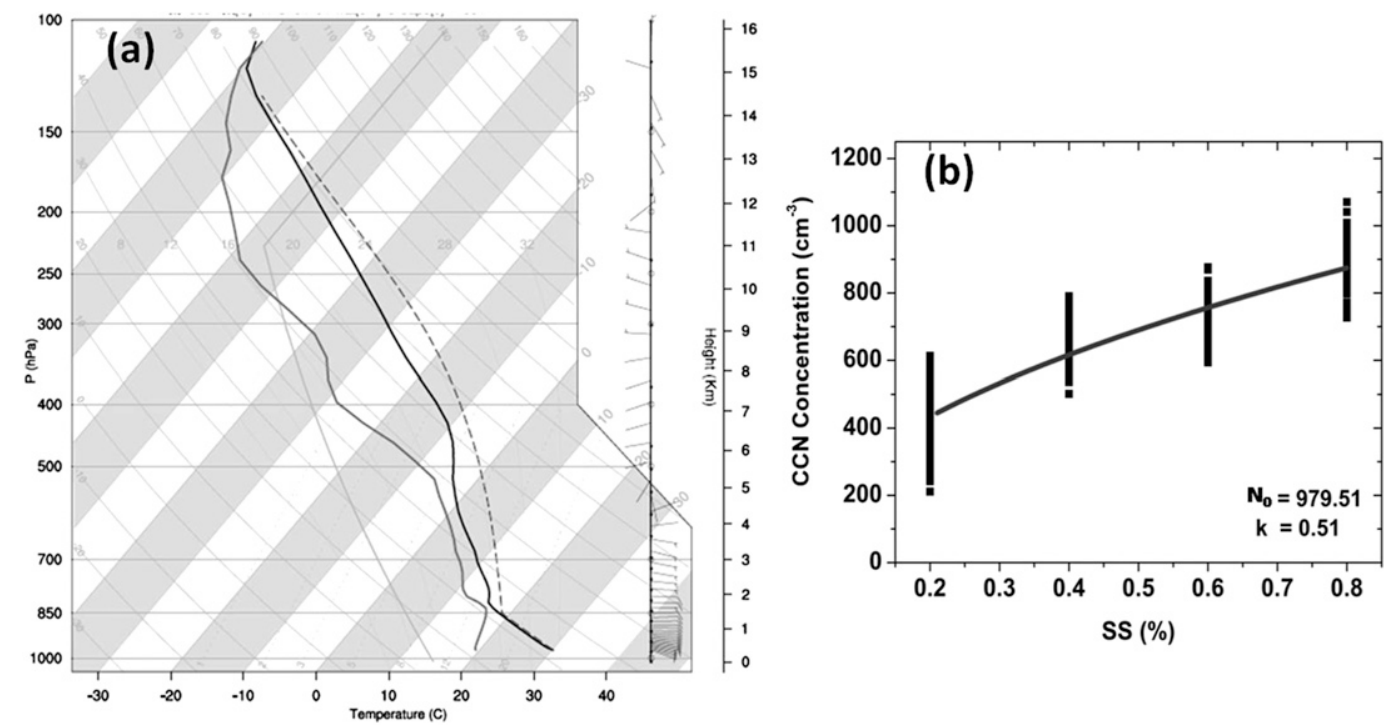

FIG. 2. (a) Skew $T$ plot of sounding at 1330 LST from the model and (b) aircraft measured CCN spectra over the study region. Each square in (b) corresponds to a CCN measurement below the cloud base at approximately 100-m intervals at different supersaturations.

attributed to the different regions (such as diluted cloud edges and adiabatic cores) profiled by aircraft during the cloud penetrations.

A skew $T$ plot at 1330 LST over the selected study region is shown in Fig. 2a. It is observed that the surface was moist with a mixing ratio of $18 \mathrm{~g} \mathrm{~kg}^{-1}$. The surface dewpoint temperature was $23^{\circ} \mathrm{C}$, indicating a warm-base cloud system. The lifting condensation level (LCL) temperature was $18^{\circ} \mathrm{C}$ and was located around the 853-hPa pressure level. The convective available potential energy (CAPE) before the formation of deep convection was $1900 \mathrm{~J} \mathrm{~kg}^{-1}$. The amount of total column precipitable water was $5 \mathrm{~cm}$. This suggests that favorable conditions were present for the formation of deep convection. From the aircraft data, it was found that subcloud aerosol concentrations were reaching as high as $3000 \mathrm{~cm}^{-3}$ with sizes ranging from 0.02 to $10 \mu \mathrm{m}$, suggesting that the cloud formed in a highly polluted environment. The $\mathrm{CCN}$ activity spectrum was estimated from Twomey's equation [Eq. (1)] using the measurements made by the $\mathrm{CCN}$ counter, which are given in Fig. 2b. Each symbol in this plot corresponds to a $\mathrm{CCN}$ measurement below cloud base at approximately $100-\mathrm{m}$ intervals at different supersaturations. The observed number concentration of $\mathrm{CCN}\left(N_{0}\right)$ at $1 \%$ supersaturation was $979 \mathrm{~cm}^{-3}$, and the slope parameter $k$ was 0.51 . Therefore, the simulation with moderate $\mathrm{CCN}\left(N_{0}=1000 \mathrm{~cm}^{-3}\right)$ was considered as a control, and that simulation was compared with aircraft observations. Land and ocean areas were initialized with the same $\mathrm{CCN}$ conditions.

\section{d. Design of numerical experiment}

WRF simulations were performed for the DCC case observed on 27 October 2011. Three two-way nested domains with a horizontal resolution of 27,9 , and $3 \mathrm{~km}$ were used with 49 vertical levels. The number of grid points in each domain is $160 \times 140,259 \times 238$, and $418 \times 313$, respectively. The 6-hourly NCEP Final Analysis (FNL) Global Analysis data on a $1^{\circ} \times 1^{\circ}$ grid with $27-\mathrm{km}$ horizontal grid size was used for initial and boundary conditions. Boundary conditions were updated every $6 \mathrm{~h}$ at the outer domain. Domain 3 (dashed white box; Fig. 1) was set over the study region where the DCC case was observed both by C-band radar and the aircraft. Simulations started at 1800 UTC 26 October and lasted for $24 \mathrm{~h}$ (up to 1800 UTC 27 October), and the first $6 \mathrm{~h}$ are regarded as model spinup time and are not used for inferences from the study. Physical parameterization options and details of the simulation are listed in Table 2. To study aerosol effects, simulations were carried out at three different initial $\mathrm{CCN}$ conditions referred to as low-CCN, control (which is closer to observed $\mathrm{CCN}$ ), and high- $\mathrm{CCN}$ conditions with initial CCN concentrations of 100, 1000, and $3000 \mathrm{~cm}^{-3}$ at $1 \%$ supersaturation $N_{0}$, respectively.

\section{Results and discussion}

\section{a. Observed size distribution}

Figure 3 shows the combined drop size distribution (DSD) and particle size distribution (PSD) spectra from 
TABLE 2. Model setup details.

\begin{tabular}{|c|c|}
\hline Model parameter & Setting \\
\hline Model grid & $\begin{array}{l}\text { Three two-way nested domains, resolutions } \\
\text { of } 27,9 \text {, and } 3 \mathrm{~km} \text {; model top } 20 \mathrm{~km}\end{array}$ \\
\hline Initialization & $\begin{array}{l}\text { 6-hourly NCEP FNL Operational Global } \\
\text { Analysis data on a } 1^{\circ} \times 1^{\circ} \text { grid }\end{array}$ \\
\hline Time step & $60 \mathrm{~s}$ \\
\hline $\begin{array}{l}\text { Duration of } \\
\text { simulation }\end{array}$ & $\begin{array}{l}24 \mathrm{~h} \text { (simulation runs from } 1800 \text { UTC } 26 \\
\text { Oct to } 1800 \text { UTC } 27 \text { Oct) }\end{array}$ \\
\hline Microphysics & $\begin{array}{l}\text { Spectral bin microphysics, fast version } \\
\text { (Khain et al. 2009, 2010) }\end{array}$ \\
\hline $\mathrm{CCN}$ setup & Initial $\mathrm{CCN}=100,1000$, and $3000 \mathrm{~cm}^{-3}$ \\
\hline Longwave scheme & $\begin{array}{l}\text { Rapid radiative transfer model scheme } \\
\text { (Mlawer et al.1997) }\end{array}$ \\
\hline Shortwave radiation & Dudhia scheme (Dudhia 1989) \\
\hline Land surface scheme & $\begin{array}{l}\text { Unified Noah land surface model } \\
\text { (Tewari et al. 2004) }\end{array}$ \\
\hline PBL scheme & $\begin{array}{l}\text { Yonsei University (YSU) scheme } \\
\text { (Hong et al. 2006) }\end{array}$ \\
\hline Cumulus scheme & $\begin{array}{l}\text { Kain-Fritsch (new eta) scheme (Kain 2004; } \\
\text { used only for two outer domains) }\end{array}$ \\
\hline
\end{tabular}

various instruments on board the aircraft measured at different temperatures in the supercooled region of the cloud. These spectra are averaged over a time period mentioned at the top of each plot where corresponding temperature, altitude, liquid water content, and vertical velocity are mentioned, respectively. Droplet and particle spectra measured by various instruments show good agreement among themselves, indicating that the measurements are reliable. Measurements indicated several modes in the spectra attributed to the cloud droplets, raindrops, and ice particles. It was noticed that peak values in the DSD decreased and broadened with altitude. It can be attributed to the drop-drop collisions and accretion of small droplets by graupel, which decreased the number concentration of small cloud drops and increased in larger drops $(>50 \mu \mathrm{m})$. To show the observed ice particle characteristics clearly, Fig. 4 presents the images from the 2DS probe at various temperatures as indicated in the figure. Each image strip is approximately $1.28 \mathrm{~mm}$ wide and $12.8 \mathrm{~mm}$ long. The 2DS probe provided information on how the particle habits varied with altitude. Note the presence of many columns, needles, chain aggregates, and graupel appear at various vertical levels. Graupel particles as large as $1 \mathrm{~mm}$ can be noticed around $6.2 \mathrm{~km}$ and were indicative of the efficient growth of ice particles by riming. It is important to note that most of the particles larger than $300 \mu \mathrm{m}$ were heavily rimed and that pristine ice particles were rarely observed (at least in the detectable range of ice particle probes). This indicates that ice particle growth by riming was the dominant process in increasing mass of ice particles. Above $6.4 \mathrm{~km}$, no graupel particles were seen. The presence of needles observed around $-6^{\circ} \mathrm{C}$ indicate the presence of the Hallett-Mossop (HM) process (Hallett and Mossop 1974) in this cloud. A previous study by Patade et al. (2016) with the use of CAIPEEX data reported that conditions were favorable in mixed-phase monsoon clouds for the HM process to be active. In addition to ice particles, the supercooled drops were also observed above freezing level.

\section{b. Cloud microphysical structure from model and observations}

The model simulation (control) was compared with available aircraft observations (Fig. 5). For the comparisons, we confined our analysis of model results to a relatively isolated DCC system over the study region (solid white box; Fig. 1a), which was profiled by aircraft, covering $15.5^{\circ}-17.0^{\circ} \mathrm{N}$ and $76.0^{\circ}-77.7^{\circ} \mathrm{E}$ (about $165 \times 162 \mathrm{~km}^{2}$ ). The profiles shown in Fig. 5 are averaged over the period from 1500 to 1800 LST. The simulated temperature $T$ and relative humidity (RH) profiles are shown in Figs. 5a and 5b, respectively. The model-simulated temperature compared well with observed temperature above the boundary layer, yet there was a negative bias in the lower levels. Modelsimulated RH was higher compared to observations except near the cloud-base region (at $1.5 \mathrm{~km}$ ). Observed RH increased in the lower levels and then decreased above cloud base. This feature is also shown in the model results. The difference in the simulated and measured RH in the boundary layer (below $1.5 \mathrm{~km}$ ) is attributed to the fact that CAIPEEX aircraft covered a large distance as the cloud base was nearly $100 \mathrm{~km}$ away (from a highly populated urban area). The cloud-base height derived from model simulations was found at $1584 \mathrm{~m}$ above ground, which was in good agreement with observations $(1535 \mathrm{~m})$.

For the comparison of cloud microphysical parameters, aircraft data were restricted to the cloudy region where cloud liquid water was greater than $0.01 \mathrm{~g} \mathrm{~m}^{-3}$ and droplet number concentration was higher than $20 \mathrm{~cm}^{-3}$. The aircraft passed through diluted and undiluted parts (Fig. 1c) of the cloud; therefore, a large scatter in the aircraft data is noted. The other simulations with perturbed CCN (100 and $3000 \mathrm{~cm}^{-3}$ ) were also shown for microphysical parameters. In the control run, modeled mean cloud droplet effective radius also showed an increase with altitude and compared well with the observations (Fig. 5c). Various studies have shown that efficient raindrop formation begins when the effective radius of cloud droplets exceeds $12-14 \mu \mathrm{m}$ (Freud et al. 2008; Konwar et al. 2012). For the low-CCN simulation $\left(100 \mathrm{~cm}^{-3}\right)$, the effective radius crossed the 

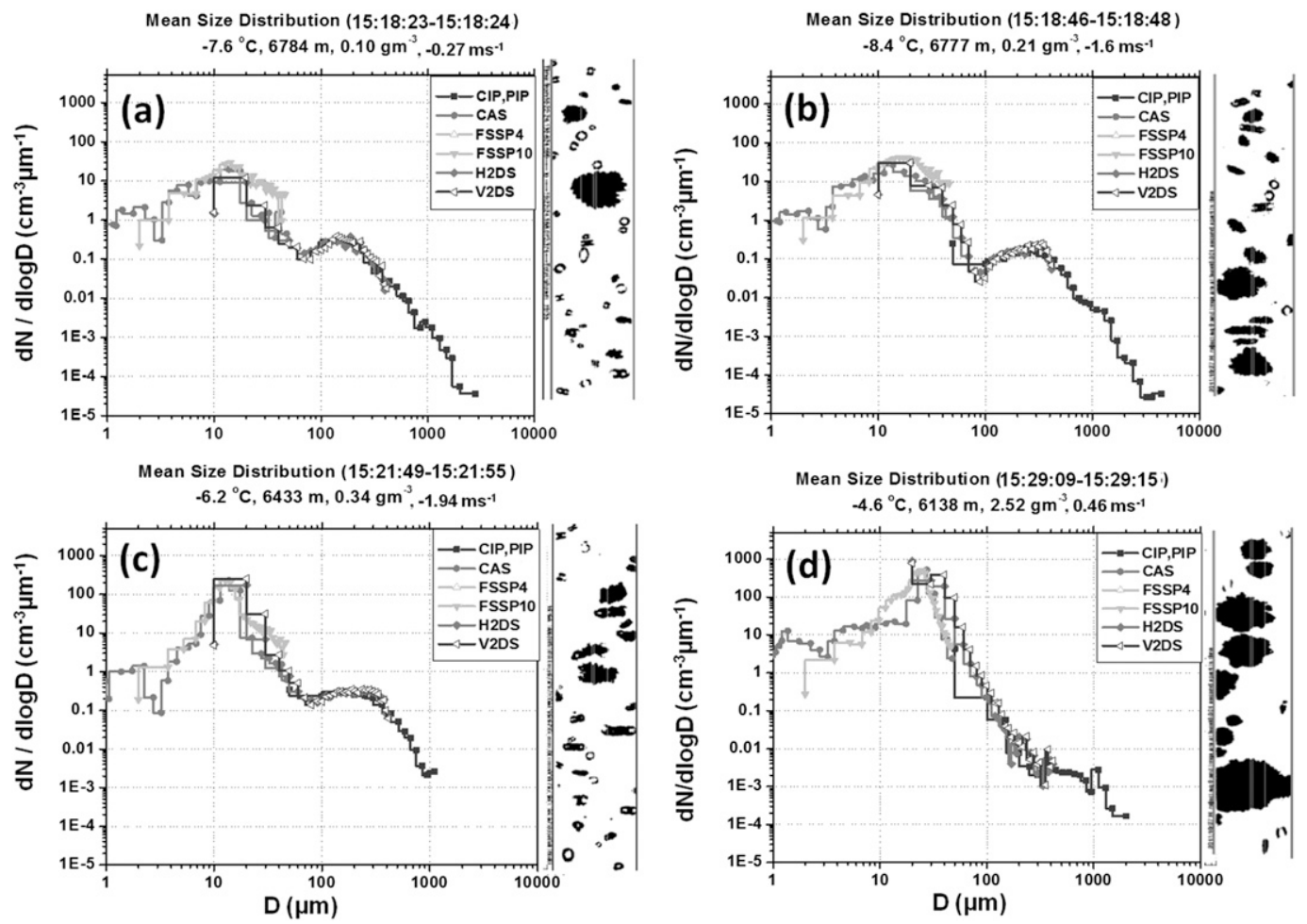

FIG. 3. Observed DSD spectra at different temperatures in the HM region, obtained from various instruments averaged over the time (LST) shown above each plot. Average $T$, altitude, LWC, and vertical velocity for corresponding section of the flight are also shown above each panel. Different symbols denote PSD derived from different instruments. A representative particle image from a 2D stereo probe for corresponding cloud pass and altitude are also provided.

$12-\mu \mathrm{m}$ threshold for warm rain initiation at $2.5 \mathrm{~km}$, whereas from the observations and control simulation, this was noted above $5.1 \mathrm{~km}$ (freezing level). For the high-CCN case, the effective radius never crossed the threshold for warm rain initiation (maximum effective radius was $8 \mu \mathrm{m}$ ), which indicates a significant delay in the first raindrop formation and most of the rain originated above freezing level. An increase in the height of raindrop formation in $T=-8.3^{\circ} \mathrm{C}, Z=6.7 \mathrm{~km}$
$W=-1.9 \mathrm{~ms}^{-1}$

$\mathrm{T}=-6.1^{\circ} \mathrm{C}, \mathrm{Z}=6.6 \mathrm{~km}$ $\mathrm{w}=-0.03 \mathrm{~ms}^{-1}$

$\mathrm{T}=-5.9^{\circ} \mathrm{C}, \mathrm{Z}=6.4 \mathrm{~km}$ $\mathrm{w}=0.6 \mathrm{~ms}^{-1}$

$\mathrm{T}=-5.6^{\circ} \mathrm{C}, \mathrm{Z}=6.2 \mathrm{~km}$ $\mathrm{w}=0.3 \mathrm{~ms}^{-1}$

$\mathrm{T}=-5.6^{\circ} \mathrm{C}, \mathrm{Z}=6.2 \mathrm{~km}$ $\mathrm{w}=1.53 \mathrm{~ms}^{-1}$

$\mathrm{T}=-5.1^{\circ} \mathrm{C}, \mathrm{Z}=6.1 \mathrm{~km}$ $\mathrm{w}=0.86 \mathrm{~ms}^{-1}$
Strip Width $=1.28 \mathrm{~mm}$

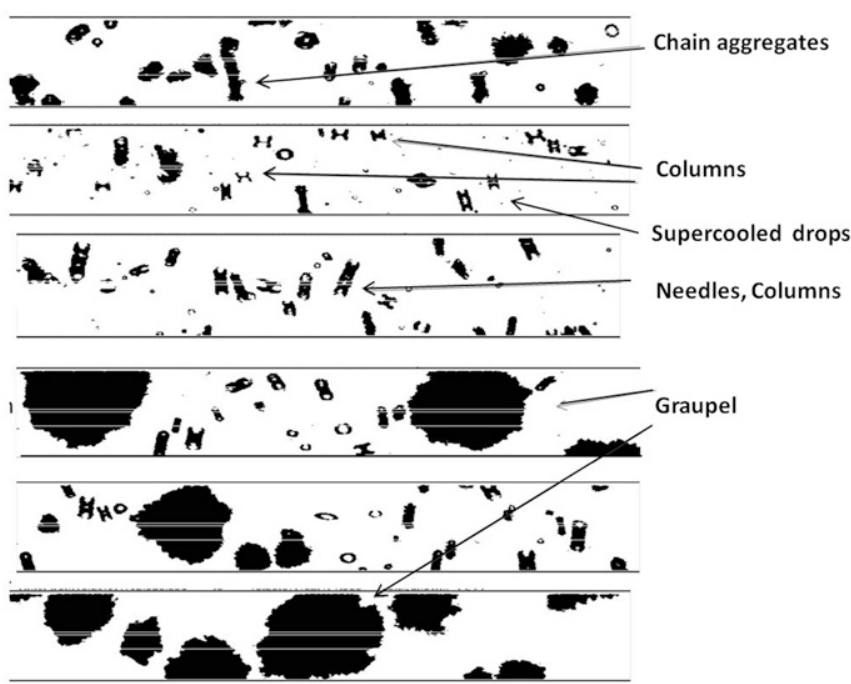

FIG. 4. Particle images from $2 \mathrm{DS}$ probe observed at various temperatures $T\left({ }^{\circ} \mathrm{C}\right)$ and corresponding altitude $Z(\mathrm{~km})$. 

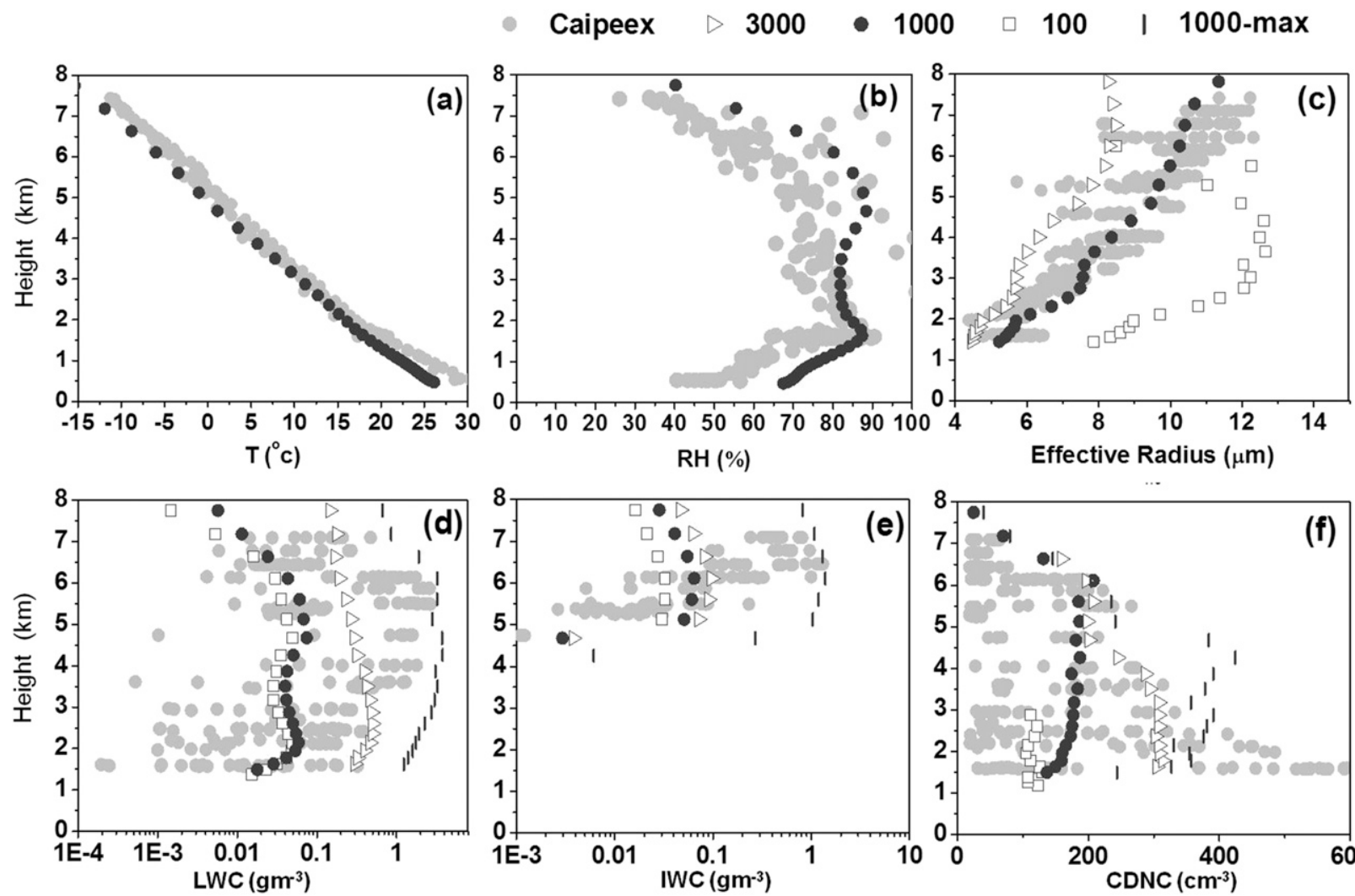

FIG. 5. Comparison of observed (CAIPEEX) and model-simulated (100, 1000, and $\left.3000 \mathrm{~cm}^{-3}\right)$ profiles of (a) $T\left({ }^{\circ} \mathrm{C}\right)$, (b) RH (\%), (c) cloud droplet effective radius $(\mu \mathrm{m})$, (d) LWC $\left(\mathrm{g} \mathrm{m}^{-3}\right)$, (e) IWC $\left(\mathrm{g} \mathrm{m}^{-3}\right)$, and (f) CDNC $\left(\mathrm{cm}^{-3}\right)$. The model results are averaged over the cloudy points for the comparison (except for $T$ and $\mathrm{RH}$, which are taken outside of cloudy points). Maximum LWC, IWC, CDNC from default simulation $\left(1000 \mathrm{~cm}^{-3}\right)$ are also show in (d)-(f).

polluted monsoon clouds was also seen from CAIPEEX observations (Prabha et al. 2011; Konwar et al. 2015) and from model simulation (Khain et al. 2013). Simulated mean LWC for the control case $\left(1000 \mathrm{~cm}^{-3}\right)$ was in fair agreement with the observations (Fig. 5d). The observed ice water content (IWC) showed an increase with altitude (Fig. 5e). The simulated total IWC (ice, snow, and graupel) showed an increase up to $6.5 \mathrm{~km}$, and then it decreased with height. The vertical variation of mean cloud droplet number concentration (CDNC) compared well with the observations (Fig. 5f). Maximum values of LWC, IWC, and CDNC from the control simulation were also presented to show the range of the given quantities.

The microphysical structure and precipitation depend on the DSD (and PSD) shape at all stages of the cloud evolution; thus, it is very crucial to get an adequate representation of DSD (and PSD) evolution with altitude for a physically realistic representation of the model processes (e.g., drop-drop and drop-ice interactions). There are further feedbacks between microphysics and dynamics that are a consequence of these initial interactions (Khain et al. 2007).
CAIPEEX observations have shown that the boundary layer moisture and subcloud aerosol number concentration have a strong influence on DSD (Prabha et al. 2011, 2012) as well as on PSD (Patade et al. 2015). The comparisons between the modeled (control case) and observed particle size distribution of cloud drops and ice particles (snow and graupel) at different altitudes and in different cloud regions (updrafts and downdrafts) are shown in Fig. 6. To compare simulated particle spectra with observations, we added both the ice categories' spectra as total ice. The top panels (Figs. 6a-d) show comparison of PSD in updrafts, and the bottom panels (Figs. 6e-h) show comparison of PSD in downdraft regions. Symbols represent observed data from various instruments, and lines represent results from the simulation. It is clear from Fig. 6 that DSDs and PSDs simulated by the model are comparable with the observations at warmer as well as colder temperatures. Both the shape and number concentrations of spectra were in good agreement. The number concentration of smaller-size droplets $(<10 \mu \mathrm{m})$ was overpredicted by the model by about an order of a 
$2.1 \mathrm{~km}\left(15^{\circ} \mathrm{C}\right)$
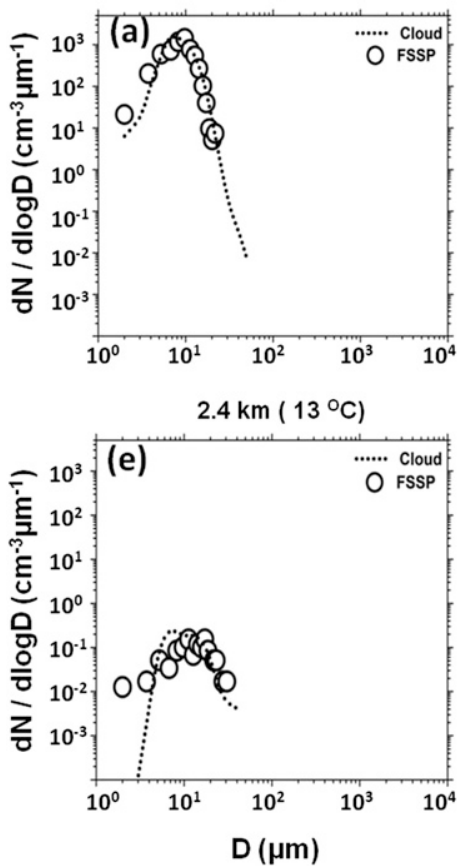

$3.6 \mathrm{~km}\left(7^{\circ} \mathrm{C}\right)$

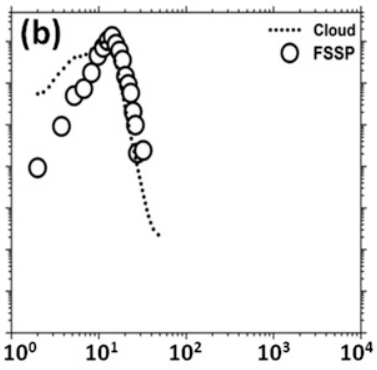

$6.1 \mathrm{~km}\left(-6^{\circ} \mathrm{C}\right)$

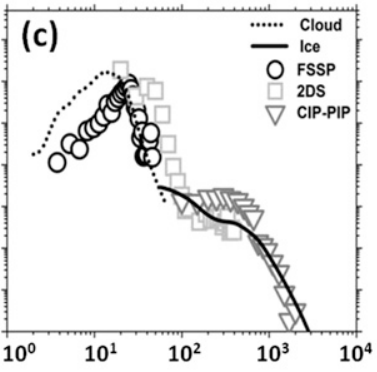

$6.7 \mathrm{~km}\left(-8^{\circ} \mathrm{C}\right)$

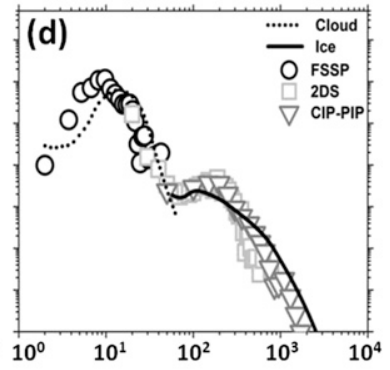

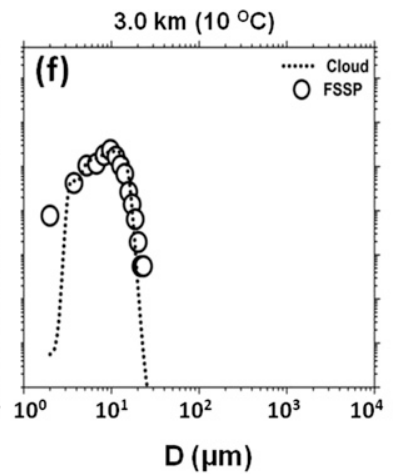
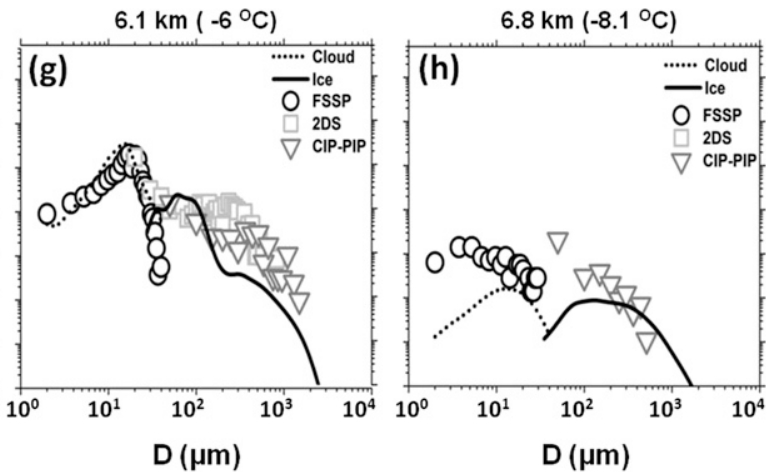

FIG. 6. Comparison between observed and simulated (from control case of $\mathrm{CCN}=1000 \mathrm{~cm}^{-3}$ ) size distribution at different altitudes in (a)-(d) updrafts and (e)-(h) downdrafts above cloud base; lines represent simulation results and symbols represent in situ aircraft measurements from different instruments as indicated.

magnitude at few levels (Figs. 6b,c). Ice particles were observed above $5 \mathrm{~km}$, and ice particle spectra match well with that of the CIP-PIP and 2DS (when available). The comparison is good in updraft regions compared to downdraft regions. It is to be noted that downdrafts will be influenced by various processes such as the entrainment and mixing and evaporation of cloud droplets and ice particles. The importance of the entrainment and mixing on droplet spectra in monsoon clouds was investigated in earlier studies (Prabha et al. 2012; Bera et al. 2016; Kumar et al. 2017), and these processes take place at several orders of scales smaller than the ones discussed in the present study. The model resolution used in the present study is not adequate to comment further on these topics. However, good agreement between observed and simulated thermodynamical, cloud microphysical quantities, and the drop and particle spectra at different levels provide confidence that our simulations were able to represent the DCC development and can be used to study aerosol effects on cloud properties and precipitation.

\section{c. Effects on surface precipitation}

To study how aerosol particles modulate cloud structure and precipitation, simulations for three different initial CCN concentrations of 100,1000 , and $3000 \mathrm{~cm}^{-3}$ were considered for the analysis. The spatial distribution of accumulated precipitation for three simulations during the time of peak convection (1730 LST) is shown in Figs. $7 \mathrm{a}-\mathrm{c}$ for the whole domain (domain 3). There are significant differences in the spatial distribution and intensity of rain between low-CNN $\left(100 \mathrm{~cm}^{-3}\right)$ and high-CCN $\left(3000 \mathrm{~cm}^{-3}\right)$ concentration. We can see an increase in precipitation over the study region for the high-CCN case (black box), especially with several highprecipitating clusters, compared to the low-CCN case. The precipitation over the Bay of Bengal (BoB) for the low-CCN case is higher, and higher numbers of small precipitation cells are seen compared to the high-CCN simulation. Accumulated surface precipitation averaged over the whole domain classified as strong $(>30 \mathrm{~mm})$ and weak ( $>0$ and $<30 \mathrm{~mm}$ ) precipitation and corresponding fractional area are presented in Table 3. Domain-average accumulated precipitation amounts of 60.4 and $5.5 \mathrm{~mm}$ over the ocean from strong and weak precipitating centers, respectively, were noted for the low-CCN case, while 63 and $6 \mathrm{~mm}$ for high-CCN conditions, respectively, were noted. The fractional area with weak and strong surface precipitation over the ocean is $61 \%$ and $8 \%$, respectively, for low-CCN conditions and $39 \%$ and $7 \%$, respectively, for high-CCN runs. This analysis indicated that weak-precipitating areas over the ocean reduced significantly by $20 \%$ for 

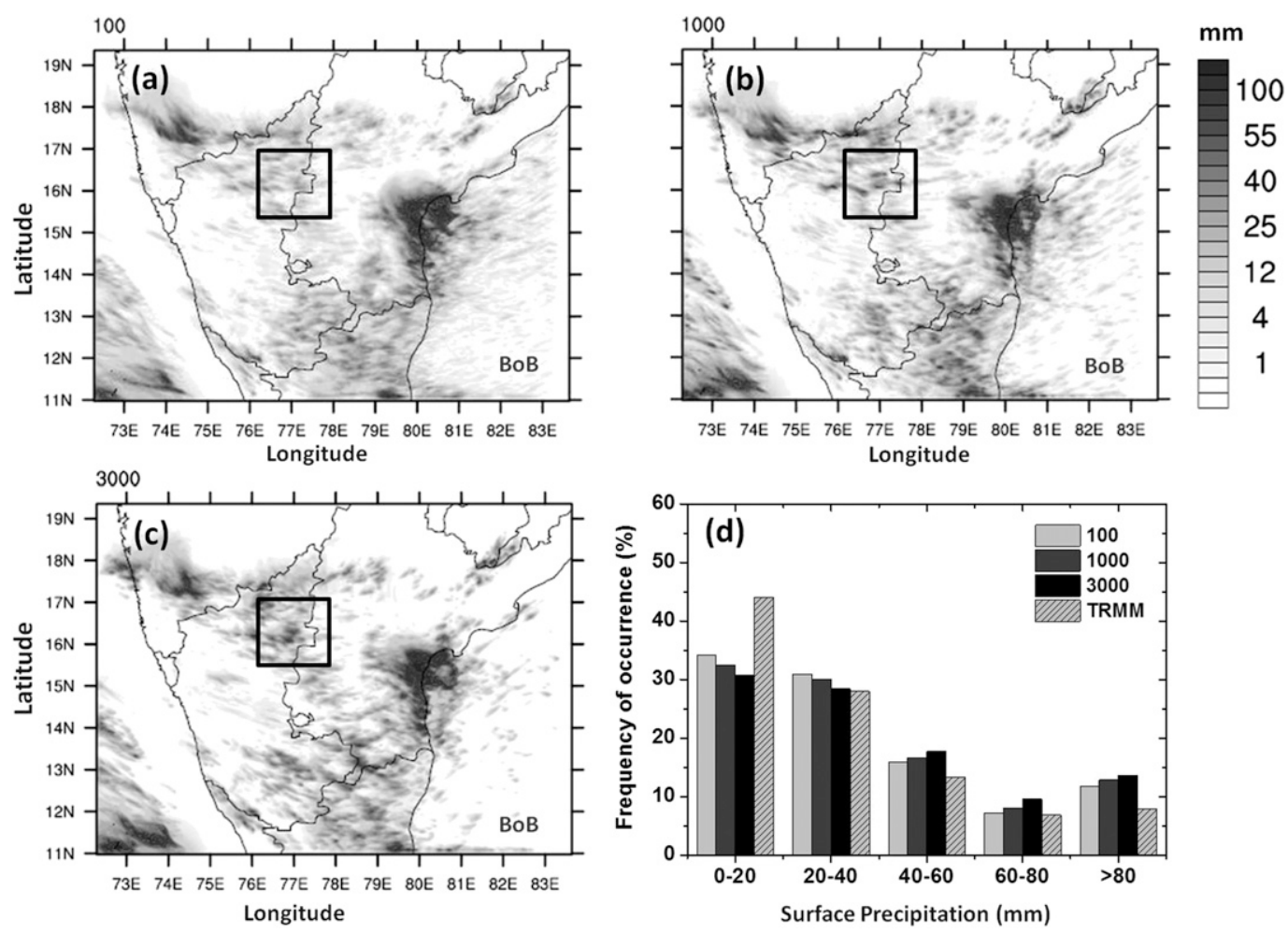

FIG. 7. Simulated spatial distribution of accumulated surface precipitation (mm) at 1730 LST with different initial CCN concentrations: (a) 100, (b) 1000, and (c) $3000 \mathrm{~cm}^{-3}$. The convective system over the study region is shown in the black box. (d) PDF (\%) of accumulated precipitation for 0600-2400 LST from simulations and TRMM. Data are shown over the whole domain.

the high-CCN case. Similarly, reduction of the fractional area for weak precipitation is noted over land. Both over land and ocean, we noted an increase in the strongprecipitation amount with high CCN. The main difference here is attributed to the difference in the rain formation mechanisms over both locations. Over the ocean, it is the warm rain formation that dominates, and over land, the cold processes bring much of the rainfall. Our main focus in the present manuscript will be on the convection over land areas, which showed increased rainfall in the heavy-surface-precipitation areas. The probability density function (PDF) for accumulated surface precipitation for 0600-2400 LST from the simulations and the Tropical Rainfall Measuring Mission (TRMM; Huffman et al. 2007) over the whole domain is shown in Fig. 7d. The TRMM compares well for few precipitation bins, although it is noted that the temporal resolution of TRMM is $3 \mathrm{~h}$. The probabilities for the precipitation amounts of 40-60-, 60-80-, and $>80-\mathrm{mm}$ bins are increased because of the increase in $\mathrm{CCN}$ concentrations. However, the overall changes in surface precipitation due to changes in $\mathrm{CCN}$ are small.

Figure 8 shows the time series of simulated liquid water path (LWP; Fig. 8a), total ice water path (IWP; Fig. 8b), accumulated rainfall (Fig. 8c), and rain rate (Fig. 8d) averaged over the study region at different initial $\mathrm{CCN}$ concentrations from the three simulations. An increase in LWP (cloud and rain) and IWP (ice, snow, and graupel) was noted with an increase in initial CCN concentration (Figs. 8a,b). The decrease in LWP after 1700 LST was associated with the occurrence of rain and removal of mass. Accumulated precipitation

TABLE 3. Domain-average surface precipitation classification over land and ocean for two CCN concentration simulations. Corresponding fractional area is shown in parentheses.

\begin{tabular}{|c|c|c|c|c|}
\hline \multirow[b]{2}{*}{$\mathrm{CCN}$} & \multicolumn{2}{|c|}{ Strong: $>30 \mathrm{~mm}$} & \multicolumn{2}{|c|}{ Weak: $>0$ and $<30 \mathrm{~mm}$} \\
\hline & Land & Ocean & Land & Ocean \\
\hline $100 \mathrm{~cm}^{-3}$ & $46.3 \mathrm{~mm}(7.8 \%)$ & $60.4 \mathrm{~mm}(8 \%)$ & $8.1 \mathrm{~mm}(63 \%)$ & $5.5 \mathrm{~mm}(61 \%)$ \\
\hline $3000 \mathrm{~cm}^{-3}$ & $48.7 \mathrm{~mm}(7.7 \%)$ & $63.2 \mathrm{~mm}(7 \%)$ & $7.8 \mathrm{~mm}(59 \%)$ & $6.0 \mathrm{~mm}(39 \%)$ \\
\hline
\end{tabular}



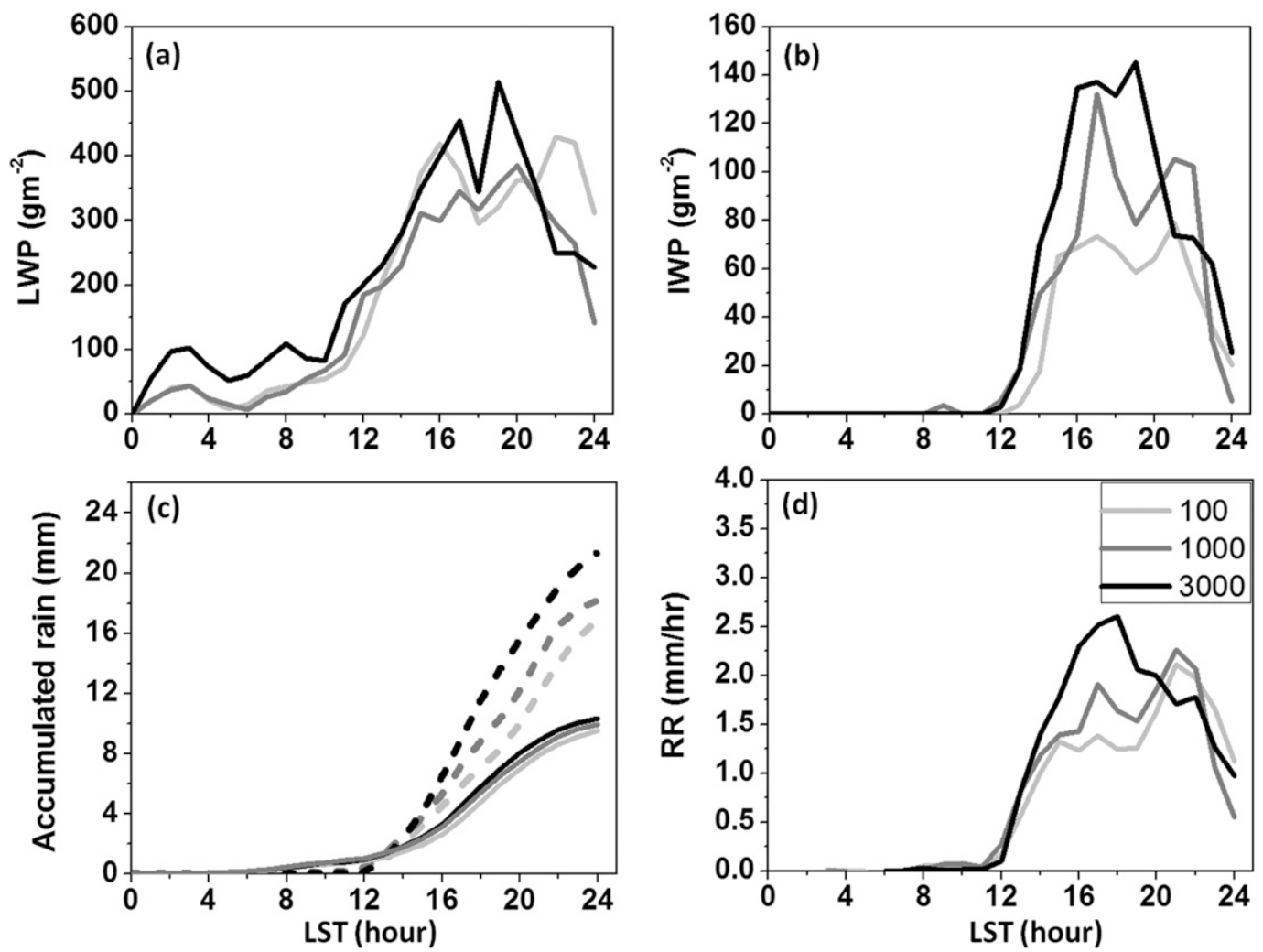

FIG. 8. Time evolution of the simulated (a) LWP, (b) IWP, (c) accumulated precipitation (dashed lines for study region and solid lines for whole domain), and (d) rain rate is averaged over the study region at three different initial concentrations of CCN: 100, 1000, and $3000 \mathrm{~cm}^{-3}$.

at the surface increased (Fig. 8c; dashed lines) under high-CCN conditions by about $25 \%$ over the study region, but when averaged over a large area (solid lines), the increase in precipitation in the high-CCN case is small (about 5\%). The results do not show a significant difference between the three simulations when considered over the whole domain. We performed this check because of the argument that the $\mathrm{CCN}$ effects on the accumulated precipitation noted over a small region may be attributed to the single realization of the case. This result is similar to the one observed by Lee and Baik (2016). They concluded that these small differences in precipitation are definitely a mixture of physical effects and due to different flow realizations. Surface rain rate $(\mathrm{RR})$ increased after $1400 \mathrm{LST}$ for the high-CCN conditions (Fig. 8d) over the study region. This increase in $\mathrm{RR}$ coincided with an increase in IWP in the high-CCN conditions, which indicates that possible ice processes contributed to the RR. The differences in other variables, LWP, IWP, and RR, over the whole domain are provided in supplementary Fig. S2, where there are many different types of clouds in the whole domain that are at different stages of their development and may also impact the judgment of the $\mathrm{CCN}$ effect on precipitation. Further in-depth studies are needed to isolate physical and coincidental effects to understand $\mathrm{CCN}$ impacts on surface precipitation.

\section{d. Effects on cloud microphysics}

Figure 9 shows the simulated vertical profiles for maximum cloud droplet number concentration $N_{c}$, mean droplet effective radius, mean cloud water content $Q_{c}$, and mean rainwater content $Q_{r}$ in the study region and their sensitivity to $\mathrm{CCN}$ concentration during 1500-1800 LST. The conditional sampling on microphysical fields was done with cloud fields averaged over points where $Q_{c}$ is greater than $0.01 \mathrm{~g} \mathrm{~m}^{-3}, Q_{r}$ averaged over points when $Q_{r}$ is greater than $0.001 \mathrm{~g} \mathrm{~m}^{-3}$, and ice fields (Fig. 10) averaged when total ice (ice, snow, and graupel) mixing ratio is larger than $0.001 \mathrm{~g} \mathrm{~m}^{-3}$. It was found that $N_{c}$ increased roughly from $100 \mathrm{~cm}^{-3}$ in the experiment with low-CCN concentration to $950 \mathrm{~cm}^{-3}$ in the experiment with high-CCN concentrations (Fig. 9a). It was interesting to see that, for the high-CCN experiment, $N_{c}$ increased above the cloud base up to a certain altitude $(\approx 4 \mathrm{~km})$ and 

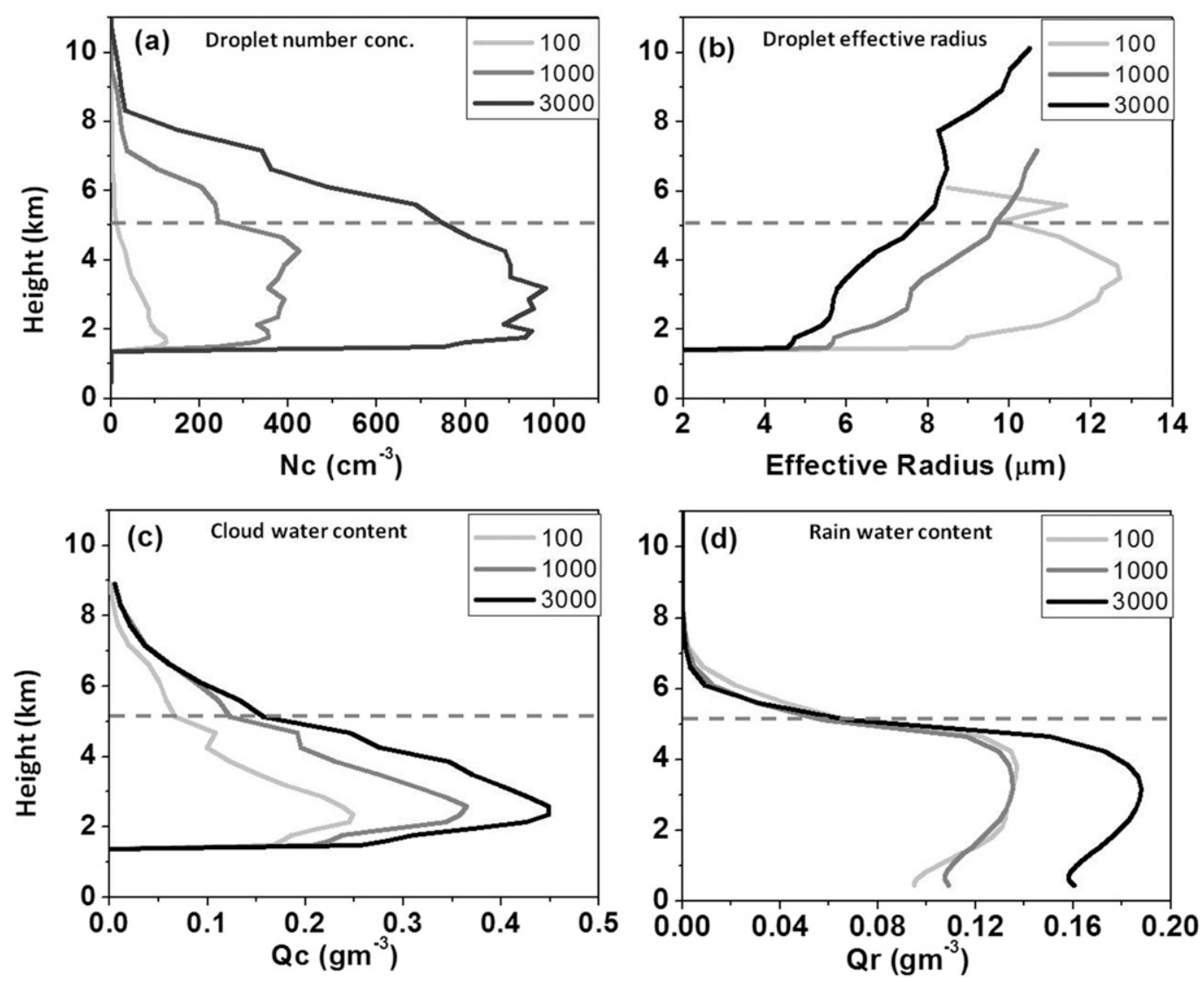

FIG. 9. Model-simulated vertical profiles of (a) maximum cloud droplet number concentration $N_{c}$, (b) mean cloud droplet effective radius, (c) average cloud water content $Q_{c}$, and (d) average rainwater content $Q_{r}$ during 1500-1800 LST at three different initial CCN concentrations $\left(100,1000\right.$, and $\left.3000 \mathrm{~cm}^{-3}\right)$ over the study region. Dashed line denotes the freezing level.

then decreased, whereas for the low-CCN experiment, $N_{c}$ decreased just above the cloud base. This is indicative of the formation of cloud droplets above the cloud base in the high-CCN case [also noted in Fig. 6 where concentrations from model showed enhancement at lower $(<10 \mu \mathrm{m})$ size ranges]. In bin microphysics, the formation of cloud drops is based on the Köhler theory. If there is sufficient $\mathrm{CCN}$ along with high vertical velocity, then there can also be in-cloud activation of cloud droplets when supersaturation is present in cloud updrafts [high vertical velocities are generally correlated with high supersaturation (Korolev and Mazin 2003)]. A decrease in droplet effective radius with an increase in $\mathrm{CCN}$ concentration was seen (Fig. 9b). In the low-CCN experiment, the effective radius exceeds the critical effective radius of $12 \mu \mathrm{m}$ at $2 \mathrm{~km}$, indicating that the warm rain process is active here. For the control and high-CCN $\left(N_{0}=3000 \mathrm{~cm}^{-3}\right)$ experiments, droplet effective radius did not cross the critical radius of $12-\mu \mathrm{m}$ size and continued to increase above the freezing level and becomes a maximum at 7 and $12 \mathrm{~km}$, respectively.
This can be explained by the fact that individual droplets grow more slowly because of the increased competition for water among the more numerous droplets (Freud et al. 2008; Khain 2009), which results in a smaller effective radius in the high- $\mathrm{CCN}$ environment. Because of smaller droplets, rain formation by the collision-coalescence mechanism is delayed, and an increase in the $Q_{c}$ at higher levels $(2.4 \mathrm{~km})$ is seen in the high-CCN environment (Fig. 9c) compared to low-CCN environment, where the peak in $Q_{c}$ is noted at $2.1 \mathrm{~km}$. Though the precipitation formation by the warm rain process was delayed, there was an increase in $Q_{r}$ with the increase in CCN concentration. This increase in $Q_{r}$ is likely due to the enhanced melting of ice hydrometeors and subsequent increase in collision-coalescence. It is important to note that the first indirect effect (smaller cloud drops with high $\mathrm{CCN}$ ) and second indirect effect (more cloud water retained in the clouds) are simulated by the model.

Figure 10 shows vertical profiles of average quantities (spatial and temporal) during 1500-1800 LST over the 

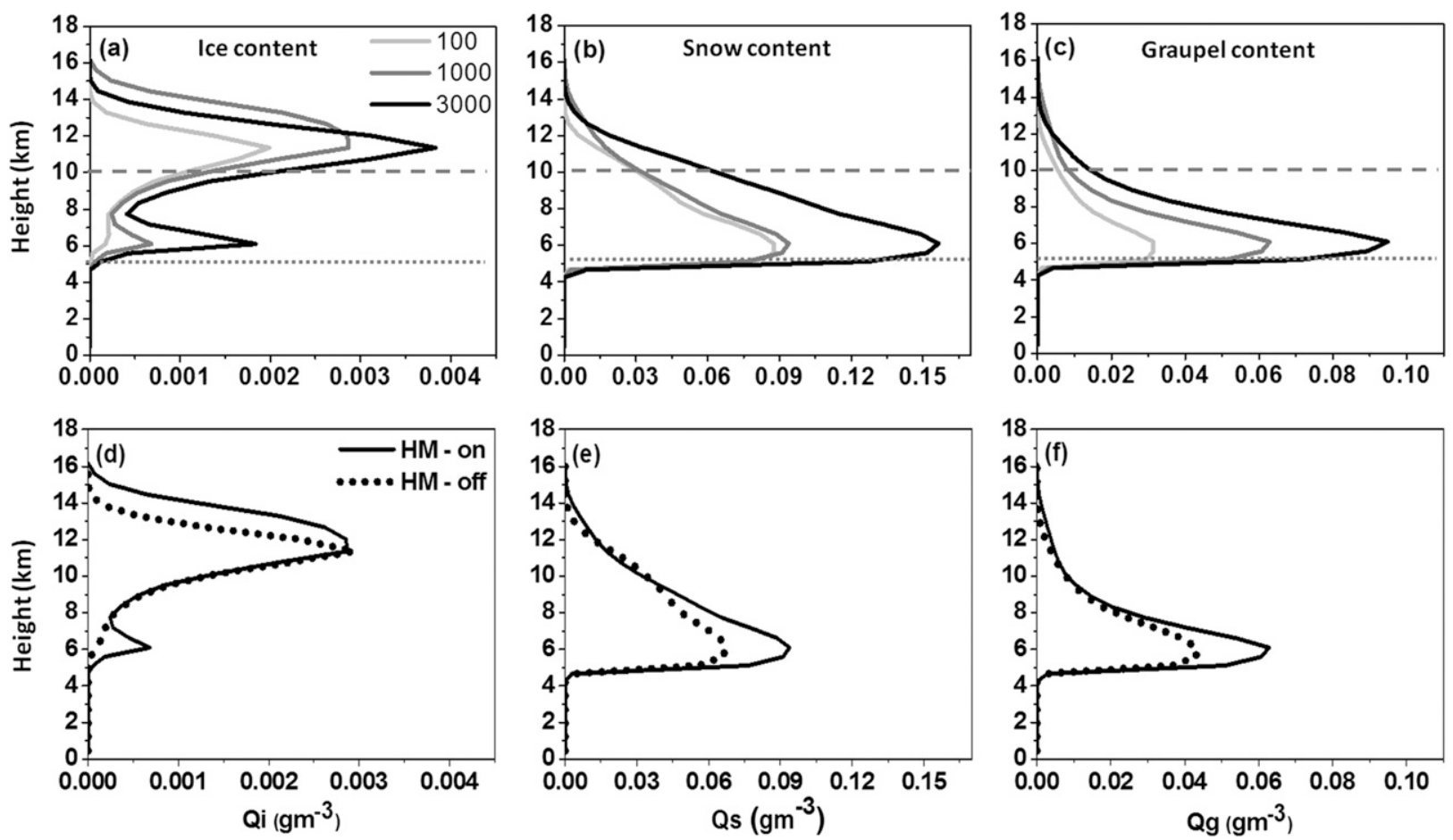

FIG. 10. Model-simulated vertical profiles of (a) cloud ice content $Q_{i}$, (b) snow water content $Q_{s}$, and (c) graupel water content $Q_{g}$ at different initial CCN concentrations $\left(100,1000\right.$, and $3000 \mathrm{~cm}^{-3}$ ) averaged over the study region during 1500-1800 LST. (d)-(f) Simulations with the HM turned off for the control simulation are also presented. Dashed line denotes the level of homogeneous freezing $\left(-39^{\circ} \mathrm{C}\right)$, and dotted line denotes the freezing level $\left(0^{\circ} \mathrm{C}\right)$.

study region. It is evident from Fig. 10 that all ice-phase hydrometeors are increased with an increase in $\mathrm{CCN}$ concentration. The vertical variation of ice crystal mass $Q_{i}$ shows bimodal structure (Fig. 10a): one at $6 \mathrm{~km}$ and another at $11 \mathrm{~km}$. The upper-level peak corresponds to deposition growth of a large number of ice particles from homogeneous freezing. The average mass of snow $Q_{s}$ (Fig. 10b) did not show a significant difference between simulations except for the high-CCN case. Snow mass is overestimated in the high- $\mathrm{CCN}$ case because the collision between large snowflakes and small water droplets leads to snow formation in simulations. Graupel content $Q_{g}$ also showed a significant increase for high-CCN conditions (Fig. 10c). The masses of graupel particles depend on the riming efficiency, which has increased because of availability of more cloud liquid water in the high-CCN case. In the SBM, graupel particle formation and growth can occur by collisions between drops and crystals and between drops and snowflakes, as well as by aggregation of ice and snow. More LWC in the high-CCN experiment thus led to the enhanced graupel formation and growth by the collision mechanism mentioned above. The presence of graupel mass above $10 \mathrm{~km}$ as noted here was also reported in few studies conducted with bin microphysics (e.g., Fan et al.
2007; Khain et al. 2004) and with bulk microphysics (Storer and van den Heever 2013; Morrison et al. 2015). To investigate the lower peak in $Q_{i}$, we made another simulation for the control case, turning off the HM process (Figs. 10d-f). In SBM at $-5^{\circ} \mathrm{C}, 1$ splinter is created per 200 droplets, with diameters over $24 \mu \mathrm{m}$ collected by riming, and the splinter production rate decreases at the end of the temperature range $\left(-3^{\circ}\right.$ to $-8^{\circ} \mathrm{C}$ ). The lower-level peak in $Q_{i}$ around $6 \mathrm{~km}$ $\left(-6^{\circ} \mathrm{C}\right)$ is clearly due to the contribution from ice mass produced by the HM process. The reduction in $Q_{i}$ in the absence of the HM process also leads to a decrease in the mass of $Q_{s}$ and $Q_{g}$ in the HM region. Thus, it appears that the HM process plays an important role in precipitation development in a monsoon environment, which is in agreement with the previous study by Patade et al. (2016), using large-eddy simulation experiments and CAIPEEX observations. The presence of needles and columns in CIP images (Fig. 4) around $-6^{\circ} \mathrm{C}$ indicates that there was significant secondary ice production by the HM process. Thus, both cloud water content and ice content increase in polluted conditions, as is noted in previous studies of convective clouds (e.g., Andreae et al. 2004; van den Heever et al. 2006; Rosenfeld et al. 2008; Sheffield et al. 2015). 


\section{e. Effect on dynamics}

The significant increase in the surface precipitation in the high-CCN experiment suggests the possibility of the invigoration effect on DCC by a dynamical feedback (e.g., Rosenfeld et al. 2008; Storer et al. 2010). Several cloud-resolving modeling studies examined the physical processes behind the aerosol invigoration effect, which are summarized by Tao et al. (2012). Studies have suggested enhancement in updraft intensity as a result of latent heat production due to diffusional growth of numerous smaller droplets and suppression of collision-coalescence in polluted conditions (e.g., Wang 2005; Khain et al. 2005; van den Heever and Cotton 2007; Storer et al. 2010; Lee et al. 2008a; Rosenfeld et al. 2008; Khain 2009). Considering the uncertainties in isolating the aerosol effects on dynamics, we investigate maximum updrafts in the simulation as well as the PDF of updrafts, latent heating rates, and updraft mass flux. Figure 11 shows the time evolution of simulated maximum updraft velocity $w$ in the study region for the whole simulation period for three simulations [low CCN (Fig. 11a), control (Fig. 11b), and high CCN (Fig. 11c)] where updrafts are greater than $1 \mathrm{~m} \mathrm{~s}^{-1}$. It was found that clouds that developed under high CCN have stronger updrafts, prominent above $5 \mathrm{~km}$. It may be indicated that higher $\mathrm{CCN}$ concentrations can significantly affect cloud dynamics over the study region. A PDF of updrafts for the whole domain at different levels (Figs. 11d-f) during the convective period (1500-1800 LST) was also investigated. There was no significant difference in the updrafts in the low- and high-CCN experiments at $5^{\circ} \mathrm{C}$ (Fig. 11d), which was similar to updrafts considered at all levels (not shown). However, at $-10^{\circ} \mathrm{C}$, we may notice a slight enhancement in updrafts (see the tail of the PDF in Fig. 11e) in the low-CCN case. At $-20^{\circ} \mathrm{C}$ (Fig. 11f), however, there is further increase in strong updrafts in the low-CCN case.

The whole-domain PDF analysis considers clouds over both land and ocean and thus involves different types of clouds (both deep and shallow), as well as at different stages of development. In the shallow clouds over the ocean, the cloud development pertains to warmer temperatures, and they precipitate faster. While condensate is removed at lower altitudes, the vertical velocities may further increase, and further cloud development may happen in the clean case. While over land, the cloud grows to higher altitudes to the cold regions to make precipitation from ice processes. However, the effects of condensate off-loading on vertical velocity are difficult to explain by numerical modeling
(Grabowski 2015). This analysis indicates that the vertical velocity distribution in the small-area statistics may convey a significantly different impression when the whole domain is considered where different types of clouds are interacting.

Figure 12 shows the averaged (over the study region during 1500-1800 LST) profiles of microphysical latent heating (and cooling) rate, updraft mass flux, and condensate loading. Two extreme experiments of CCN regime $\left(100\right.$ and $\left.3000 \mathrm{~cm}^{-3}\right)$ are presented for the sake of simplicity. In Fig. 12a, solid lines correspond to positive values of heating and indicate the contribution from condensation, deposition, and freezing; dotted lines correspond to cooling as a result of the effects of evaporation, sublimation, and melting. Clouds that developed in the high-CCN experiment produced more heating and cooling compared to the low-CCN experiment. Latent heating by warm-phase processes was higher than the cold and mixed-phase processes. In the warm region, more heat was released because of enhanced droplet activation and vapor depositional growth of small droplets. Whereas in the cold region, latent heating was generated by vapor deposition onto ice and freezing of liquid during riming. The increase in the cooling at $5 \mathrm{~km}$ for the high-CCN experiment was due to drop evaporation and enhanced melting in the melting layer $(5.1 \mathrm{~km})$. As can be summarized, the overall effect was an increase in net heating with greater contribution from warm-phase processes.

Average profiles of convective updraft mass flux are shown in Fig. 12b. Here, we defined the updraft mass flux to be the product of air density and vertical velocity for all grid points where $w \geq 1 \mathrm{~m} \mathrm{~s}^{-1}$ in the study region. Simulated mass flux associated with the high-CCN case was larger than that for the low-CCN case. This result is supported by studies that have shown an increase in the updraft mass flux under polluted conditions (van den Heever et al. 2006; Tao et al. 2007; Lee et al. 2008b; Lee and Feingold 2013; van den Heever et al. 2011; Fan et al. 2014; Lebo and Morrison 2014). A decrease in the updraft mass flux above $8 \mathrm{~km}$ was seen. To explain this further, the vertical profile of condensate loading for low and high CCN was investigated. The condensate loading is a product of acceleration due to gravity and total condensate (cloud, rain, ice, snow, and graupel) mixing ratio. There was an increase in condensate loading in the high-CCN case throughout the column with more contribution from the cold phase. The enhanced liquid and ice mass in the high-CCN experiment exerted a drag to average updraft speeds because of the weight of the condensate that led to a decrease in updraft mass flux at higher levels. Similar results have also been shown by 

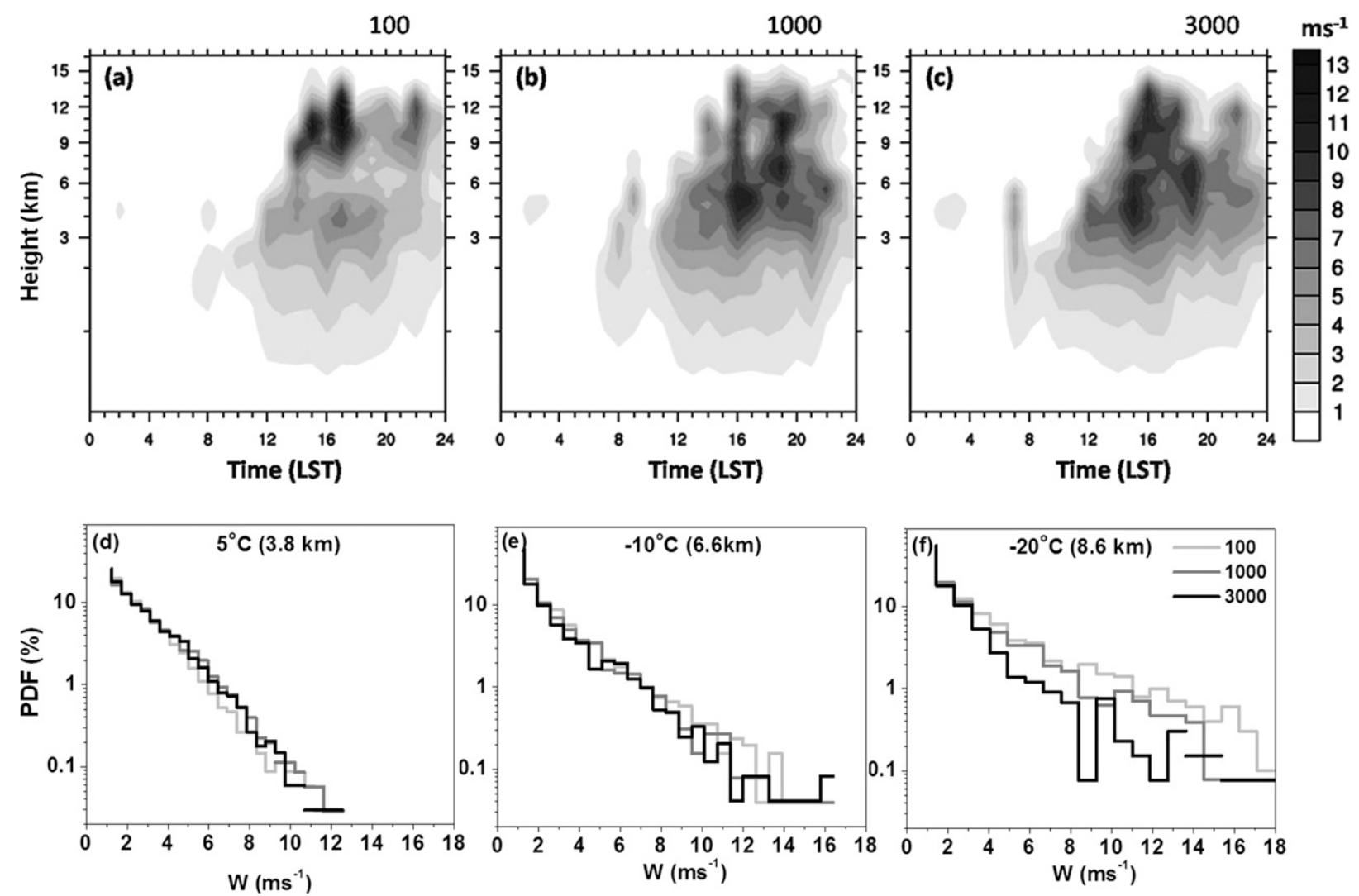

FIG. 11. (top) Time evolution of vertical profiles of simulated maximum updraft in the selected study region for CCN concentrations of (a) 100 , (b) 1000 , and (c) $3000 \mathrm{~cm}^{-3}$ where updrafts are greater than $1 \mathrm{~m} \mathrm{~s}^{-1}$. (bottom) PDFs (\%) over the whole domain at (d) $5^{\circ}$, (e) $-10^{\circ}$, and (f) $-20^{\circ} \mathrm{C}$ during $1500-1800 \mathrm{LST}$ are also shown.

Storer and van den Heever (2013), Sheffield et al. (2015), and Saleeby et al. (2015).

\section{f. Effect on cloud drop and particle spectra}

To illustrate the effect of an increase in $\mathrm{CCN}$ on the DSD and PSD, Fig. 13 shows the simulated droplet mass distribution (Figs. 13a,b) and graupel mass distribution (Figs. 13c,d) spectra at different altitudes for two extreme CCN concentrations [low $\left(100 \mathrm{~cm}^{-3}\right)$ and high $\left.\left(3000 \mathrm{~cm}^{-3}\right)\right]$. These spectra are averaged for the cloudy points where updrafts were greater than $2 \mathrm{~m} \mathrm{~s}^{-1}$ at 1700 LST. The DSD (Figs. 13a,b) clearly showed two modes: one for cloud droplets (left peak; less than $50 \mu \mathrm{m}$ ) and one for raindrops (right). Under high-CCN
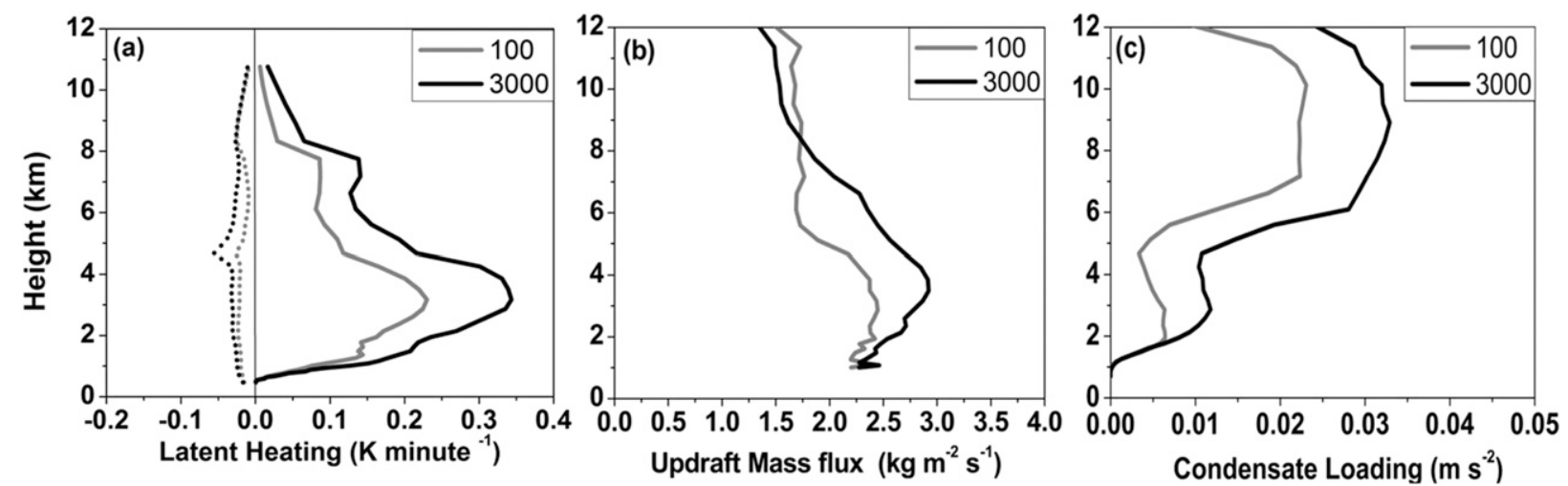

FIG. 12. Vertical profiles of simulated (a) latent heating rate (dotted lines represent latent cooling), (b) updraft mass flux, and (c) condensate loading

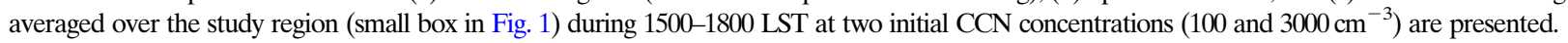



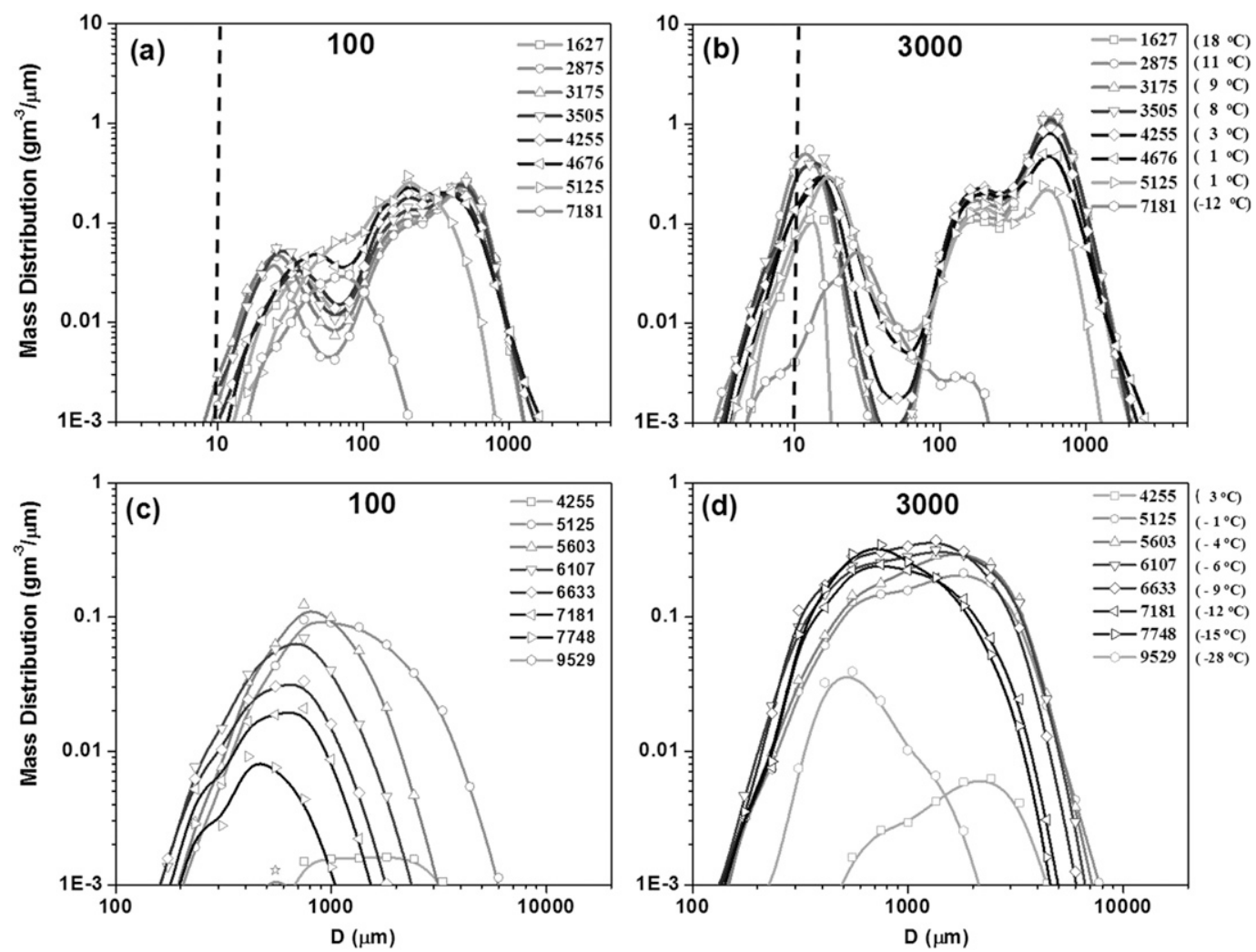

FIG. 13. Simulated mass distribution spectra at different altitudes for (a),(b) liquid water and (c),(d) graupel with initial CCN concentrations of 100 and $3000 \mathrm{~cm}^{-3}$. These spectra are averaged for the cloudy points where updrafts were greater than $2 \mathrm{~m} \mathrm{~s}^{-1}$ at $1700 \mathrm{LST}$. Markers indicate altitudes (m); approximate values of temperature $\left({ }^{\circ} \mathrm{C}\right)$ at corresponding altitudes are supplied in brackets.

conditions, the peak of cloud droplet spectra was shifted to smaller diameter; however, the cloud droplet mass was increased. As the $\mathrm{CCN}$ concentration increases, more droplets are activated, resulting in an increase in droplet mass. The raindrop spectra (right peak in Figs. 13a,b) was slightly shifted to the larger diameter, and there was an increase in the raindrop mass especially for diameters larger than $400 \mu \mathrm{m}$ under the high-CCN environment. As the $\mathrm{CCN}$ concentration is increased, the size distribution of liquid drops changed, leading to a change in ice-phase processes such as riming and melting. This can be seen in the graupel mass spectra (Figs. 13c,d), which became broader, and graupel mass was increased with an increase in $\mathrm{CCN}$ concentration. Also, the graupel mass was seen at higher levels because of stronger updrafts in the high-CCN experiment compared to the low-CCN experiment. Under high CCN, snow mass content (supplementary Fig. S3) also showed an increase; however, the broadening of the snow spectra was not prominent at this time step. Previous studies have shown that riming is more efficient when the diameter of cloud droplets is larger than $10 \mu \mathrm{m}$ (Pitter and Pruppacher 1973;
Muhlbauer et al. 2010). In our study, though, the cloud drop spectra shifted to smaller size under high $\mathrm{CCN}$; there was an increase in drops between 10 and $30 \mu \mathrm{m}$ in diameter. This promoted an increase in riming, leading to an enhancement in the graupel mass. In addition, the melting of ice-phase particles contributed to larger drops (greater than $400 \mu \mathrm{m}$ ). These large drops further promoted collision-coalescence that affected the raindrop size distribution, leading to wider DSDs and an increase in precipitation at the surface. Similar results were noted by several other studies (Fan et al. 2007; Cheng et al. 2010; Han et al. 2012; Cui et al. 2011; Xiao et al. 2015). The sensitivity of riming to $\mathrm{CCN}$ concentration varies from case to case and from model to model (Muhlbauer et al. 2010). Hence, more studies with bin microphysics are needed to provide detailed insights on the effects of changing $\mathrm{CCN}$ on DSD under different conditions.

\section{g. Cloud fraction and cloud mass flux across the melting layer}

Cloud fraction profiles averaged over the entire domain (Fig. 14a) and over the simulation period except 

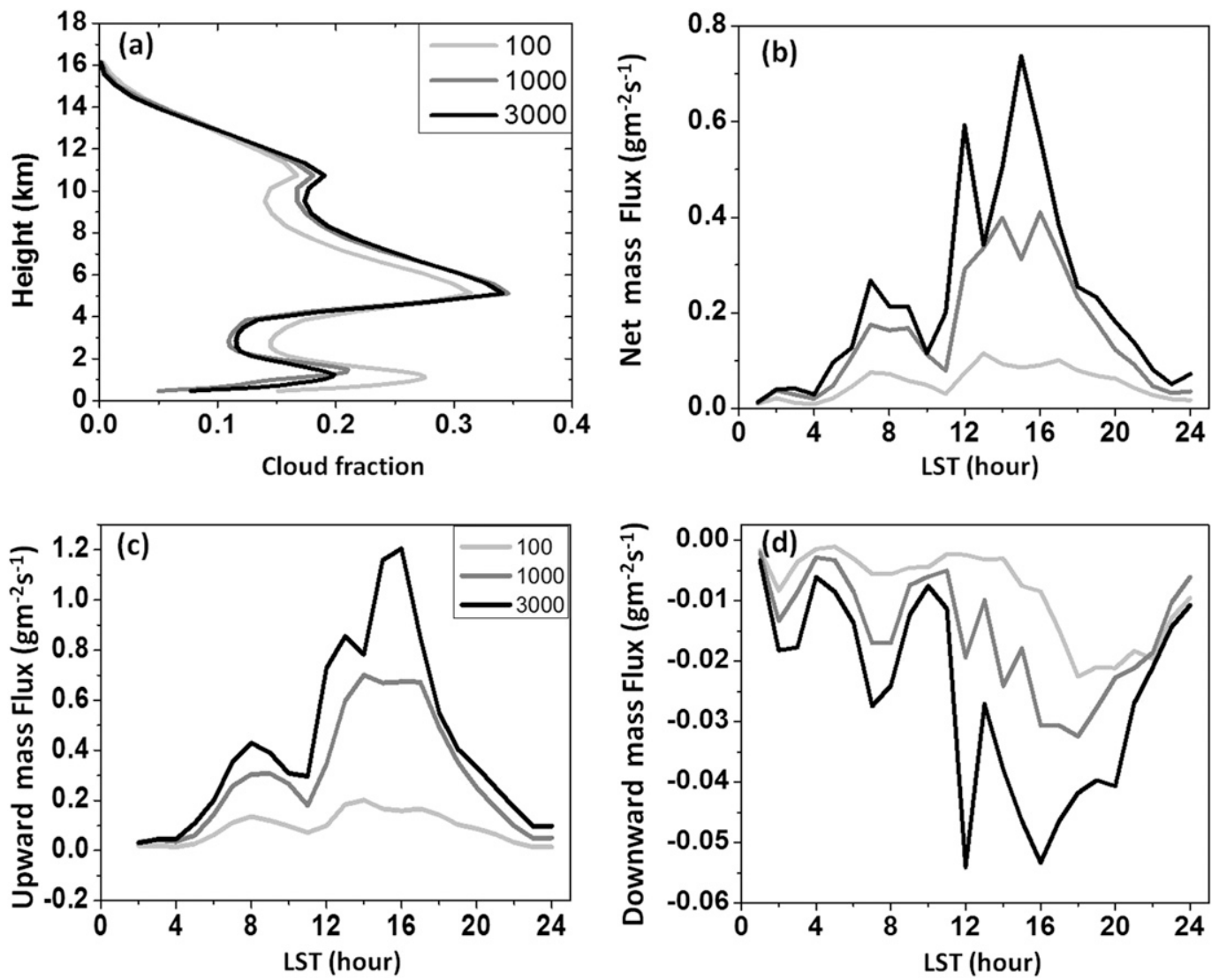

FIG. 14. (a) Whole-domain average cloud fraction during 0600-2400 LST, (b) time series of net cloud mass flux, and (c) upward and (d) downward mass fluxes across freezing level $\left(\mathrm{g} \mathrm{m}^{-2} \mathrm{~s}^{-1}\right)$ for three initial CCN concentrations $\left(100,1000\right.$, and $\left.3000 \mathrm{~cm}^{-3}\right)$ are presented.

the spinup time of $6 \mathrm{~h}$ are considered. Cloud fraction is defined as the fraction of grid points where the total condensed water mixing ratio exceeds $0.01 \mathrm{~g} \mathrm{~m}^{-3}$. Cloud fraction profiles show a decrease in cloud fraction below freezing level and an increase in cloud fraction above freezing level for the high-CCN case compared to the low-CCN case. This interesting difference is further investigated by looking at the net upward and downward cloud mass flux time series across the freezing level over the entire domain (Figs. 14b-d). The cloud mass flux is defined as the product of total condensed water and air velocity. The upward and downward cloud mass flux across the freezing level always remained high in the high-CCN case; however, a sharp increase was noted after 1100 LST and peaked at 1600 LST. This important finding on downward cloud mass flux across this level draws the conclusion that most of the increase in surface rainfall came from the ice processes in a high-CCN case. However, suppression of warm rain for the high-CCN case, together with raindrops lofted above freezing level in strong updrafts and the presence of maximum cloud liquid water at higher altitudes as supercooled liquid [as illustrated in Prabha et al. (2011), Khain et al. (2013), and Patade et al. $(2015,2016)]$ has been instrumental for the intense ice- and mixed-phase processes. Thus, the preference of the microphysical regime became important for the net surface rainfall.

The domain-averaged parameters (Table 4) showed similar enhancement for all hydrometeor masses with high CCN. The microphysical parameters averaged over the entire domain do show similarities with parameters over the study region (as presented in Figs. 9 and 10); however, the magnitude of increase is much smaller. An increase in precipitation by about $5 \%$ was seen in the high-CCN case when averaged over entire domain; however, updrafts did not show much increase with increase in $\mathrm{CCN}$ concentration, as one may expect. The accumulated (over the total simulation period) net precipitation flux at freezing level showed a prominent increase in the high-CCN environment. The arguments for cloud invigoration under high $\mathrm{CCN}$ needs further essential analysis involving various process rate evaluations and investigation on the dynamic feedback. Morrison and Grabowski (2011) suggested that the 
TABLE 4. Quantities averaged over inner domain.

\begin{tabular}{lcc}
\hline \hline & Low CCN & High CCN \\
\hline$Q_{c}\left(\mathrm{~g} \mathrm{~m}^{-3}\right)$ & 0.097 & 0.196 \\
$Q_{i}\left(\mathrm{~g} \mathrm{~m}^{-3}\right)$ & 0.028 & 0.029 \\
$Q_{s}\left(\mathrm{~g} \mathrm{~m}^{-3}\right)$ & 0.120 & 0.121 \\
$Q_{g}\left(\mathrm{~g} \mathrm{~m}^{-3}\right)$ & 0.038 & 0.045 \\
$Q_{r}\left(\mathrm{~g} \mathrm{~m}^{-3}\right)$ & 0.125 & 0.133 \\
Updrafts $\left(\mathrm{m} \mathrm{s}^{-1}\right)$ & 3.34 & 3.41 \\
Downdrafts $\left(\mathrm{m} \mathrm{s}^{-1}\right)$ & -0.080 & -0.093 \\
Precipitation $(\mathrm{mm})$ & 9.44 & 9.94 \\
Accumulated precipitation flux & 1.07 & 4.88 \\
$\quad$ at melting level $\left(\mathrm{g} \mathrm{m}^{-2} \mathrm{~s}^{-1}\right)$ & & \\
\hline
\end{tabular}

invigoration mechanism is applicable when a single cloud or a cloud system is considered. On a large scale, changes in convective strength would be reduced over time because of the adjustment of the environment. In a recent study, Grabowski and Morrison (2016) investigated the convective invigoration mechanism by using a piggybacking approach and suggested that the increase in the cloud fractions comes purely from the microphysical consideration and not through convective dynamics. We noted a $5 \%$ increase in the high-cloud fraction in the high-CCN case and almost $50 \%$ reduction (in the high-CCN case) of the low-cloud fraction during the active precipitating time of simulation. We argue that the ice-phase processes and associated cloud mass flux (although with a marginal increase) has contributed to a small domain-averaged increase in precipitation. It is also to be noted that several studies have shown that thermodynamic invigoration is insignificant (e.g., Fan et al. 2009, 2013; Tao et al. 2007; Lebo and Seinfeld 2011; Grabowski and Morrison 2016). The increase in cloud depth and cloud cover when thermodynamic invigoration is inefficient as explained by Fan et al. (2013) may also be explored.

\section{Discussion and conclusions}

In this study, the Weather Research and Forecasting (WRF) mesoscale model coupled with spectral bin microphysics scheme was used to simulate deep convective clouds on 27 October 2011 over the rain-shadow region of the Indian Peninsula. There exist no comparative studies based on bin microphysics over this region and for the type of clouds observed. The key aspect in the present study is a physical evaluation of simulations in reproducing the vertical structure of the particle size distributions from observations in the warm- and mixedphase regions of clouds. In contrast to many other studies using spectral bin microphysics (SBM) for the simulation of single clouds in two dimensions (e.g., Tao et al. 2007; Li et al. 2009; Khain et al. 2012, 2015), a cloud ensemble over a larger region was investigated for a longer time period. For the first time, size distributions were studied using unique combined data obtained from CAIPEEX observational campaign and model simulation. The simulations were in good agreement with actual observations, especially for vertical variation of cloud drop size distributions (DSDs) and particle size distributions (PSDs), liquid water content, effective radius, and temperature. Thus, the model simulations were reliable to investigate the aerosol effects over this region.

Three numerical experiments were conducted with different initial cloud condensation nuclei (CCN) concentrations [low $\left(100 \mathrm{~cm}^{-3}\right)$, control $\left(1000 \mathrm{~cm}^{-3}\right)$, and high $\left.\left(3000 \mathrm{~cm}^{-3}\right)\right]$ based on the observations available from CAIPEEX to study the CCN effects on deep convective clouds over the study region. A detailed analysis showed that in the high-CCN experiment, a decrease in the effective radius of cloud drops was seen, which narrowed the cloud DSD spectra and resulted in the suppression of the collision-coalescence process, which is consistent with the earlier studies (Fan et al. 2007; van den Heever et al. 2011; Rosenfeld 1999). However, there was a sufficient number of droplets available within the size range of $10-30 \mu \mathrm{m}$ in diameter to enhance the growth of ice particles by riming to form graupel particles, which is supported by much broader graupel spectra. Results were consistent with the previous studies, which showed an increase in graupel mass under polluted conditions due to efficient riming (Wang 2005; Fan et al. 2007; Khain et al. 2011; van den Heever et al. 2006; Fan et al. 2014; Xiao et al. 2015) and were inconsistent with the earlier modeling studies that showed less graupel production under polluted conditions due to inefficient riming (Seifert and Beheng 2006; Storer and van den Heever 2013; Saleeby et al. 2011, 2013; Xue et al. 2012; Gibbons et al. 2016).

The surface precipitation increased up to $20 \%$ in localized convective cores as $\mathrm{CCN}$ increases over the study region. This enhancement in surface rainfall is reduced to $5 \%$ on domain (domain 3; indicated in Fig. 1a with dashed line box) averaging. There have been many studies suggesting that the total precipitation over a large analysis area is less sensitive to the aerosol perturbation. Long-term realistic simulations have reported a $5 \%$ increase in the 24 -h area-averaged precipitation (Seifert et al. 2012). Grabowski and Morrison (2016) also reported a 10\% increase in 12 -h accumulated precipitation in a polluted case, where the main difference with the clean case was attributed to the dynamical effects. Fan et al. (2013) reported less significant impact on the surface precipitation but a large impact on the cloud fraction. 
In conclusion, the $\mathrm{CCN}$ impacts on the mixed- and icephase processes are more important for precipitation formation. The impact on cloud fraction was relatively small compared to the results of Fan et al. (2013), where microphysical invigoration was proposed. Though the maximum updraft was stronger in convective cores over the smaller area of the high-CCN case, the updrafts over the whole domain were stronger for the low-CCN case. The main effect on ice microphysics was the production of large-size graupel due to intensification of riming. It lead to the formation of large precipitation particles (especially larger than $400 \mu \mathrm{m}$ ) via melting that efficiently collected cloud droplets and promoted the collisioncoalescence process, and this is one of the mechanisms of increasing precipitation efficiency and precipitation itself. The presence of the HM process was found to be instrumental in the development of ice, snow, and ice and graupel mass in the HM region. The 5\% increase in precipitation over the whole domain could not be attributed to thermodynamic invigoration in our study. Over the land regions, there was no significant increase in the fractional areas of high precipitation $(>30 \mathrm{~mm})$ with an increase in $\mathrm{CCN}$. However, over the ocean, the fractional area of low precipitation $(>0$ and $<30 \mathrm{~mm}$ ) has decreased by $20 \%$ for the high- $\mathrm{CCN}$ case. A subsequent study will address the physical mechanisms by looking into microphysical process rates relating to the rain formation mechanisms in mixed-phase clouds. With the present study being the first investigation over India with bin microphysics and intercomparison with direct observations of the size distributions, more case studies are needed to strongly substantiate whether the convective invigoration mechanism is active over the region.

Acknowledgments. The CAIPEEX project and IITM are fully funded by the Ministry of Earth Sciences (MoES), The Government of India, New Delhi. CAIPEEX data are the property of MoES, India, and part of the data is available on request from the program website (http://www.tropmet.res.in/ caipeex/). Authors are thankful to several IITM scientists for their contributions to the CAIPEEX project. Authors thank the director of IITM for the encouragement in carrying out this work. Gayatri Kulkarni and Sachin Patade are supported by an IITM research fellowship, and this work is also part of their Ph.D. theses. The authors would like to acknowledge the contribution from D. Axisa, previously at NCAR and now at Droplet Measurement Technologies, Inc., for the scientific discussions, for the aircraft data processing, and for the several suggestions on this research. The authors thank Aaron Bansemer, MMM-NCAR, for his expert advice and constant help with the CIP data analysis. Authors would like to thank
Dr. Resmi E. A. for radar images. The valuable suggestions and comments from Professor A. Khain and Dr. Barry Lynn improved the manuscript considerably. Data used in the present study can be made available on contacting thara@tropmet.res.in.

\section{REFERENCES}

Abhik, S., M. Haldar, P. Mukhopadhyay, X. Jiang, and B. N. Goswami, 2013: A possible new mechanism for northward propagation of boreal summer intraseasonal oscillations based on TRMM and MERRA reanalysis. Climate Dyn., 40, 1611-1624, doi:10.1007/s00382-012-1425-x.

Altaratz, O., I. Koren, L. A. Remer, and E. Hirsch, 2014: Review: Cloud invigoration by aerosols-Coupling between microphysics and dynamics. Atmos. Res., 140-141, 38-60, doi:10.1016/j.atmosres.2014.01.009.

Andreae, M. O., D. Rosenfeld, P. Artaxo, A. A. Costa, G. P. Frank, K. M. Longo, and M. A. F. Silva-Dias, 2004: Smoking rain clouds over the Amazon. Science, 303, 1337-1342, doi:10.1126/ science.1092779.

Balachandran, S., and M. Rajeevan, 2007: Sensitivity of surface radiation budget to clouds over the Asian monsoon region. J. Earth Syst. Sci., 116, 159-169, doi:10.1007/s12040-007-0016-4.

Bera, S., T. V. Prabha, and W. W. Grabowski, 2016: Observations of monsoon convective cloud microphysics over India and role of entrainment-mixing. J. Geophys. Res. Atmos., 121, 9767-9788, doi:10.1002/2016JD025133.

Cheng, C. T., W. C. Wang, and J. P. Chen, 2010: Simulation of the effects of increasing cloud condensation nuclei on mixedphase clouds and precipitation of a front system. Atmos. Res., 96, 461-476, doi:10.1016/j.atmosres.2010.02.005.

Cui, Z. Q., S. Davies, K. S. Carslaw, and A. M. Blyth, 2011: The response of precipitation to aerosol through riming and melting in deep convective clouds. Atmos. Chem. Phys., 11, 3495-3510, doi:10.5194/acp-11-3495-2011.

Dudhia, J., 1989: Numerical study of convection observed during the Winter Monsoon Experiment using a mesoscale twodimensional model. J. Atmos. Sci., 46, 3077-3107, doi:10.1175/ 1520-0469(1989)046<3077:NSOCOD >2.0.CO;2.

Fan, J., R. Zhang, G. Li, and W.-K. Tao, 2007: Effects of aerosols and relative humidity on cumulus clouds. J. Geophys. Res., 112, D14204, doi:10.1029/2006JD008136.

, and Coauthors, 2009: Dominant role by vertical wind shear in regulating aerosol effects on deep convective clouds. J. Geophys. Res., 114, D22206, doi:10.1029/2009JD012352.

_ L. R. Leung, D. Rosenfeld, Q. Chen, Z. Li, J. Zhang, and H. Yan, 2013: Microphysical effects determine macrophysical response for aerosol impacts on deep convective clouds. Proc. Natl. Acad. Sci. USA, 110, E4581-E4590, doi:10.1073/pnas.1316830110.

, and Coauthors, 2014: Aerosol impacts on California winter clouds and precipitation during CalWater 2011: Local pollution versus long-range transported dust. Atmos. Chem. Phys., 14, 81-101, doi:10.5194/acp-14-81-2014.

—, Y. Wang, D. Rosenfeld, and X. Liu, 2016: Review of aerosolcloud interactions: Mechanisms, significance, and challenges. J. Atmos. Sci., 73, doi:10.1175/JAS-D-16-0037.1.

Freud, E., D. Rosenfeld, M. O. Andreae, A. A. Costa, and P. Artaxo, 2008: Robust relations between $\mathrm{CCN}$ and the vertical evolution of cloud drop size distribution in deep convective clouds. Atmos. Chem. Phys., 8, 1661-1675, doi:10.5194/acp-8-1661-2008. 
Gibbons, M., Q. Min, and J. Fan, 2016: Investigating the impacts of Saharan dust on tropical deep convection using spectral bin microphysics, part 1: Ice formation and cloud properties. Atmos. Chem. Phys. Discuss., doi:10.5194/acp-2016-368.

Goswami, B. N., V. Venugopal, D. Sengupta, M. S. Madhusoodanan, and P. K. Xavier, 2006: Increasing trend of extreme rain events over India in a warming environment. Science, 314, 1442-1445, doi:10.1126/science.1132027.

Grabowski, W. W., 2015: Untangling microphysical impacts on deep convection applying a novel modeling methodology. J. Atmos. Sci., 72, 2446-2464, doi:10.1175/JAS-D-14-0307.1.

— deep convection applying a novel modeling methodology. Part II: Double-moment microphysics. J. Atmos. Sci., 73, 3749-3770, doi:10.1175/JAS-D-15-0367.1.

Hallett, J., and S. C. Mossop, 1974: Production of secondary ice particles during the riming process. Nature, 249, 26-28, doi:10.1038/249026a0.

Han, J.-Y., J.-J. Baik, and A. P. Khain, 2012: A numerical study of urban aerosol impacts on clouds and precipitation. J. Atmos. Sci., 69, 504-520, doi:10.1175/JAS-D-11-071.1.

Harikishan, G., B. Padmakumari, R. S. Maheskumar, G. Pandithurai, and Q. Min, 2014: Macrophysical and microphysical properties of monsoon clouds over a rain shadow region in India from ground-based radiometric measurements. J. Geophys. Res. Atmos., 119, 4736-4749, doi:10.1002/2013JD020872.

Hazra, A., V. Mandal, and J.-P. Chen, 2013a: Study of cloud microphysical properties over India during CAIPEEX using a mesoscale model with new cloud microphysical scheme-Part I. J. Atmos. Sol.-Terr. Phys., 93, 29-44, doi:10.1016/j.jastp.2012.11.010.

_ B. N. Goswami, and J.-P. Chen, 2013b: Role of interactions between aerosol radiative effect, dynamics, and cloud microphysics on transitions of monsoon intraseasonal oscillations. J. Atmos. Sci., 70, 2073-2087, doi:10.1175/JAS-D-12-0179.1.

Hong, S. Y., Y. Noh, and J. Dudhia, 2006: A new vertical diffusion package with an explicit treatment of entrainment processes. Mon. Wea. Rev., 134, 2318-2341, doi:10.1175/MWR3199.1.

Huffman, G. J., and Coauthors, 2007: The TRMM multisatellite precipitation analysis (TMPA): Quasi-global, multiyear, combined-sensor precipitation estimates at fine scales. J. Hydrometeor., 8, 38-55, doi:10.1175/JHM560.1.

Kain, J. S., 2004: The Kain-Fritsch convective parameterization: An update. J. Appl. Meteor., 43, 170-181, doi:10.1175/ 1520-0450(2004)043<0170:TKCPAU > 2.0.CO;2.

Khain, A. P., 2009: Notes on state-of-the-art investigations of aerosol effects on precipitation: A critical review. Environ. Res. Lett., 4, 015004, doi:10.1088/1748-9326/4/1/015004.

_- M. Ovtchinnikov, M. Pinsky, A. Pokrovsky, and H. Krugliak, 2000: Notes on the state-of-the-art numerical modeling of cloud microphysics. Atmos. Res., 55, 159-224, doi:10.1016/ S0169-8095(00)00064-8.

—, A. Pokrovsky, M. Pinsky, A. Seifert, and V. Phillips, 2004: Simulation of effects of atmospheric aerosols on deep turbulent convective clouds using a spectral microphysics mixedphase cumulus cloud model. Part I: Model description and possible applications. J. Atmos. Sci., 61, 2963-2982, doi:10.1175/ JAS-3350.1.

— D. Roseenfeld, and A. Pokrovsky, 2005: Aerosol impact on the dynamics and microphysics of deep convective clouds. Quart. J. Roy. Meteor. Soc., 131, 2639-2663, doi:10.1256/qj.04.62.

_ N. N. Cohen, Y. Segal, B. Lynn, and D. Rosenfeld, 2007: Effects of aerosols on lightning and intensity of tropical cyclones. Proc. 24th
General Assembly, Perugia, Italy, International Union of Geodesy and Geophysics, 986. [Available online at http://iugg.org/archive/ iugg2007perugia/www.iugg2007perugia.it/iuggProc/JM.pdf.]

_, N. Benmoshe, and A. Pokrovsky, 2008: Factors determining the impact of aerosols on surface precipitation from clouds: Attempt of classification. J. Atmos. Sci., 65, 1721-1748, doi:10.1175/2007JAS2515.1.

— L. L. R. Leung, B. Lynn, and S. Ghan, 2009: Effects of aerosols on the dynamics and microphysics of squall lines simulated by spectral bin and bulk parameterization schemes. J. Geophys. Res., 114, D22203, doi:10.1029/2009JD011902.

_ B. B. Lynn, and J. Dudhia, 2010: Aerosol effects on intensity of landfalling hurricanes as seen from simulations with the WRF Model with spectral bin microphysics. J. Atmos. Sci., 67, 365-384, doi:10.1175/2009JAS3210.1.

_ D. Rosenfeld, A. Pokrovsky, U. Blahak, and A. Ryzhkov, 2011: The role of CCN in precipitation and hail in a midlatitude storm as seen in simulations using a spectral (bin) microphysics model in a 2D dynamic frame. Atmos. Res., 99, 129-146, doi:10.1016/j.atmosres.2010.09.015.

— V. Phillips, N. Benmoshe, and A. Pokrovsky, 2012: The role of small soluble aerosols in the microphysics of deep maritime clouds. J. Atmos. Sci., 69, 2787-2807, doi:10.1175/ 2011JAS3649.1.

_, T. V. Prabha, N. Benmoshe, G. Pandithurai, and M. Ovchinnikov, 2013: The mechanism of first raindrops formation in deep convective clouds. J. Geophys. Res. Atmos., 118, 9123-9140, doi:10.1002/jgrd.50641.

_ _ and Coauthors, 2015: Representation of microphysical processes in cloud-resolving models: Spectral (bin) microphysics versus bulk parameterization. Rev. Geophys., 53, 247-322, doi:10.1002/2014RG000468.

Konwar, M., R. S. Maheshkumar, J. R. Kulkarni, E. Freud, B. N. Goswami, and D. Rosenfeld, 2012: Aerosol control on depth of warm rain in convective clouds. J. Geophys. Res., 117, D13204, doi:10.1029/2012JD017585.

— A. S. Panicker, D. Axisa, and T. V. Prabha, 2015: Near-cloud aerosols in monsoon environment and its impact on radiative forcing. J. Geophys. Res. Atmos., 120, 1445-1457, doi:10.1002/ 2014JD022420.

Korolev, A. V., and I. P. Mazin, 2003: Supersaturation of water vapor in clouds. J. Atmos. Sci., 60, 2957-2976, doi:10.1175/ 1520-0469(2003)060<2957:SOWVIC >2.0.CO;2.

Kulkarni, J. R., and Coauthors, 2012: The Cloud Aerosol Interactions and Precipitation Enhancement Experiment (CAIPEEX): Overview and preliminary results. Curr. Sci., 102, 413-425.

Kumar, B., S. Bera, T. V. Prabha, and W. W. Grabowski, 2017: Cloud-edge mixing: Direct numerical simulation and observations in Indian monsoon clouds. J. Adv. Model. Earth Syst., 9, 332-353, doi:10.1002/2016MS000731.

Kumar, S., A. Hazra, and B. N. Goswami, 2014: Role of interaction between dynamics, thermodynamics and cloud microphysics on summer monsoon precipitating clouds over the Myanmar coast and the Western Ghats. Climate Dyn., 43, 911-924, doi:10.1007/s00382-013-1909-3.

Lebo, Z. J., and J. H. Seinfeld, 2011: Theoretical basis for convective invigoration due to increased aerosol concentration. Atmos. Chem. Phys., 11, 5407-5429, doi:10.5194/ acp-11-5407-2011.

— turbations on simulated idealized squall lines. Mon. Wea. Rev., 142, 991-1009, doi:10.1175/MWR-D-13-00156.1. 
Lee, H., and J.-J. Baik, 2016: Effects of turbulence-induced collision enhancement on heavy precipitation: The 21 September 2010 case over the Korean Peninsula. J. Geophys. Res. Atmos., 121, 12 319-12 342, doi:10.1002/2016JD025168.

Lee, S. S., and G. Feingold, 2013: Aerosol effects on the cloud-field properties of tropical convective clouds. Atmos. Chem. Phys., 13, 6713-6726, doi:10.5194/acp-13-6713-2013.

_ L. J. Donner, V. T. J. Phillips, and Y. Ming, 2008a: The dependence of aerosol effects on clouds and precipitation on cloud-system organization, shear and stability. J. Geophys. Res., 113, D16202, doi:10.1029/2007JD009224.

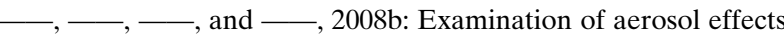
on precipitation in deep convective clouds during the 1997 ARM summer experiment. Quart. J. Roy. Meteor. Soc., 134, 1201-1220, doi:10.1002/qj.287.

Li, X., W.-K. Tao, A. P. Khain, J. Simpson, and D. E. Johnson, 2009: Sensitivity of a cloud-resolving model to bulk and explicit bin microphysical schemes. Part 2: Cloud microphysics and storm dynamics interaction. J. Atmos. Sci., 66, 22-40, doi:10.1175/2008JAS2647.1.

Liu, C., 2011: Rainfall contributions from precipitation systems with different sizes, convective intensities, and durations over the tropics and subtropics. J. Hydrometeor., 12, 394-412, doi:10.1175/2010JHM1320.1.

Mlawer, E., J. Steven, J. Taubman, P. D. Brown, M. J. Iacono, and S. A. Clough, 1997: Radiative transfer for inhomogeneous atmosphere: RRTM, a validated correlated-k model for the longwave. J. Geophys. Res., 102, 16663-16682, doi:10.1029/ 97JD00237.

Morrison, H., and W. W. Grabowski, 2011: Cloud-system resolving model simulations of aerosol indirect effects on tropical deep convection and its thermodynamic environment. Atmos. Chem. Phys., 11, 10 503-10 523, doi:10.5194/acp-11-10503-2011.

_ J. A. Milbrandt, G. H. Bryan, K. Ikeda, S. A. Tessendorf, and G. Thompson, 2015: Parameterization of cloud microphysics based on the prediction of bulk ice particle properties. Part 2: Case study comparisons with observations and other schemes. J. Atmos. Sci., 72, 312-339, doi:10.1175/JAS-D-14-0066.1.

Muhlbauer, A., T. Hashino, L. Xue, A. Teller, U. Lohmann, R. Rasmussen, I. Geresdi, and Z. Pan, 2010: Intercomparison of aerosol-cloud-precipitation interactions in stratiform orographic mixed-phase clouds. Atmos. Chem. Phys., 10, 8173-8196, doi:10.5194/acp-10-8173-2010.

Nair, S., E. A. Resmi, G. Kulkarni, N. Malap, S. Patade, and T. V. Prabha, 2015: Thermodynamical and cloud microphysical response during the transition from southwest to northeast monsoon, Atmos. Res., 166, 182-194, doi:10.1016/ j.atmosres.2015.06.018.

Narkhedkar, S. G., S. B. Morwal, B. Padmakumari, C. G. Deshpande, D. R. Kothawale, R. S. Maheskumar, and J. R. Kulkarni, 2014: Rainfall mechanism over the rain-shadow region of north peninsular India. Climate Dyn., 45, 1493-1512, doi:10.1007/s00382-014-2403-2.

Patade, S., T. V. Prabha, D. Axisa, K. Gayatri, and A. Heymsfield, 2015: Particle size distribution properties in mixedphase monsoon clouds from in situ measurements during CAIPEEX. J. Geophys. Res. Atmos., 120, 10 418-10 440, doi:10.1002/2015JD023375.

_- S. Shete, N. Malap, K. Gayatri, and T. V. Prabha, 2016: Observational and simulated cloud microphysical features of rain formation in the mixed phase clouds observed during CAIPEEX. Atmos. Res., 169, 32-45, doi:10.1016/ j.atmosres.2015.09.018.
Pitter, R., and H. Pruppacher, 1973: A wind tunnel investigation of freezing of small water drops falling at terminal velocity in air. Quart. J. Roy. Meteor. Soc., 99, 540-550, doi:10.1002/ qj.49709942111.

Prabha, T. V., A. Khain, R. S. Maheshkumar, G. Pandithurai, J. R. Kulkarni, M. Konwar, and B. N. Goswami, 2011: Microphysics of premonsoon and monsoon clouds as seen from in situ measurements during the Cloud Aerosol Interaction and Precipitation Enhancement Experiment (CAIPEEX). J. Atmos. Sci., 68, 1882-1901, doi:10.1175/2011JAS3707.1.

- and Coauthors, 2012: Spectral width of premonsoon and monsoon clouds over Indo-Gangetic valley. J. Geophys. Res., 117, D20205, doi:10.1029/2011JD016837.

Rajeevan, M., P. Rohini, K. Niranjan Kumar, J. Srinivasan, and C. K. Unnikrishnan, 2013: A study of vertical cloud structure of the Indian summer monsoon using CloudSat data. Climate Dyn., 40, 637-650, doi:10.1007/s00382-012-1374-4.

Rao, Y. P., 1976: Southwest Monsoon. Meteor. Monogr., No. 1/1976, India Meteorological Department, $379 \mathrm{pp}$.

Ravi Kiran, V., M. Rajeevan, H. Gadhavi, S. Vijaya Bhaskara Rao, and A. Jayaraman, 2015: Role of vertical structure of cloud microphysical properties on cloud radiative forcing over the Asian monsoon region. Climate Dyn., 45, 3331-3345, doi:10.1007/s00382-015-2542-0.

Rosenfeld, D., 1999: TRMM observed first direct evidence of smoke from forest fires inhibiting rainfall. Geophys. Res. Lett., 26, 3105-3108, doi:10.1029/1999GL006066.

, U. Lohmann, G. B. Raga, C. D. O'Dowd, M. Kulmala, S. Fuzzi, A. Reissell, and M. O. Andreae, 2008: Flood or drought: How do aerosols affect precipitation? Science, 321, 1309-1313, doi:10.1126/science.1160606.

Saleeby, S. M., W. R. Cotton, and J. D. Fuller, 2011: The cumulative impact of cloud droplet nucleating aerosol on orographic snowfall in Colorado. J. Appl. Meteor. Climatol., 50, 604-625, doi:10.1175/2010JAMC2594.1.

- _ - D. Lowenthal, and J. Messina, 2013: Aerosol impact on the microphysical growth processes of orographic snowfall. J. Appl. Meteor. Climatol., 52, 834-852, doi:10.1175/ JAMC-D-12-0193.1.

, S. R. Herbener, S. C. van den Heever, and T. L'Ecuyer, 2015: Impacts of cloud droplet-nucleating aerosols on shallow tropical convection. J. Atmos. Sci., 72, 1369-1385, doi:10.1175/ JAS-D-14-0153.1.

Sarangi, C., S. N. Tripathi, S. Tripathi, and M. C. Barth, 2015: Aerosol-cloud associations over Gangetic basin during a typical monsoon depression event using WRF-Chem simulation. J. Geophys. Res. Atmos., 120, 10 974-10 995, doi:10.1002/ 2015JD023634.

— - — V. P. Kanawade, I. Koren, and D. S. Pai, 2016: Investigation of the aerosol-cloud-rainfall association over the Indian summer monsoon region. Atmos. Chem. Phys., 17, 5185-5204, doi:10.5194/acp-17-5185-2017.

Seifert, A., and K. D. Beheng, 2006: A two-moment cloud microphysics parameterization for mixed-phase clouds. Part 2: Maritime vs. continental deep convective storms. Meteor. Atmos. Phys., 92, 67-82, doi:10.1007/s00703-005-0113-3.

C. Köhler, and K. D. Beheng, 2012: Aerosol-cloudprecipitation effects over Germany as simulated by a convective-scale numerical weather prediction model. Atmos. Chem. Phys., 12, 709-725, doi:10.5194/acp-12-709-2012.

Sengupta, K., S. Dey, and M. Sarkar, 2013: Structural evolution of monsoon clouds in the Indian CTCZ. Geophys. Res. Lett., 40, 5295-5299, doi:10.1002/grl.50970. 
Sheffield, A. M., S. M. Saleeby, and S. C. van den Heever, 2015: Aerosol-induced mechanisms for cumulus congestus growth. J. Geophys. Res. Atmos., 120, 8941-8952, doi:10.1002/ 2015JD023743.

Skamarock, W. C., J. B. Klemp, J. Dudhia, D. O. Gill, D. M. Barker, W. Wang, and J. G. Powers, 2005: A description of the Advanced Research WRF version 2. NCAR Tech. Note NCAR/TN-468+STR, 88 pp., doi:10.5065/D6DZ069T.

Storer, R. L., and S. C. van den Heever, 2013: Microphysical processes evident in aerosol forcing of tropical deep convective clouds. J. Atmos. Sci., 70, 430-446, doi:10.1175/JAS-D-12-076.1.

,$- \ldots$, and G. L. Stephens, 2010: Modeling aerosol impacts on convection under differing storm environments. J. Atmos. Sci., 67, 3904-3915, doi:10.1175/2010JAS3363.1.

$\longrightarrow,-$, and T. S. L'Ecuyer, 2014: Observations of aerosol-induced convective invigoration in the tropical east Atlantic. J. Geophys. Res. Atmos., 119, 3963-3975, doi:10.1002/2013JD020272.

Tao, W.-K., X. Li, A. Khain, T. Matsui, S. Lang, and J. Simpson, 2007: Role of atmospheric aerosol concentration on deep convective precipitation: Cloud-resolving model simulations. J. Geophys. Res., 112, D24S18, doi:10.1029/2007JD008728.

—, J.-P. Chen, Z. Li, C. Wang, and C. Zhang, 2012: Impact of aerosols on convective clouds and precipitation. Rev. Geophys., 50, RG2001, doi:10.1029/2011RG000369.

Tewari, M., and Coauthors, 2004: Implementation and verification of the unified Noah land surface model in the WRF Model. 20th Conf. on Weather Analysis and Forecasting/16th Conf. on Numerical Weather Prediction, Seattle, WA, Amer. Meteor. Soc., 14.2a. [Available online at https://ams.confex.com/ams/ 84Annual/webprogram/Paper69061.html.]

Urankar, G., T. V. Prabha, G. Pandithurai, P. Pallavi, D. Achuthavarier, and B. N. Goswami, 2012: Aerosol and cloud feedbacks on surface energy balance over selected regions of the Indian subcontinent. J. Geophys. Res., 117, D04210, doi:10.1029/2011JD016363.

van den Heever, S. C., and W. R. Cotton, 2007: Urban aerosol impacts on downwind convective storms. J. Appl. Meteor. Climatol., 46, 828-850, doi:10.1175/JAM2492.1.

— , G. G. Carrió, W. R. Cotton, P. J. Demott, and A. J. Prenni, 2006: Impacts of nucleating aerosol on Florida storms. Part I: Mesoscale simulations. J. Atmos. Sci., 63, 1752-1775, doi:10.1175/JAS3713.1.

—, G. L. Stephens, and N. B. Wood, 2011: Aerosol indirect effects on tropical convection characteristics under conditions of radiative-convective equilibrium. J. Atmos. Sci., 68, 699-718, doi:10.1175/2010JAS3603.1.

Varghese, M., and Coauthors, 2016: Airborne and ground based CCN spectral characteristics: Inferences from CAIPEEX-2011. Atmos. Environ., 125, 324-336, doi:10.1016/ j.atmosenv.2015.06.041.

Wang, C., 2005: A model study of the response of tropical deep convection to the increase of cloud condensation nuclei concentration: 1. Dynamics and microphysics. J. Geophys. Res., 110, D21211, doi:10.1029/2004JD005720.

Xiao, H., Y. Yin, L. Jin, Q. Chen, and J. Chen, 2015: Simulation of the effects of aerosol on mixed-phase orographic clouds using the WRF Model with a detailed bin microphysics scheme. J. Geophys. Res. Atmos., 120, 8345-8358, doi:10.1002/ 2014JD022988.

Xue, L., A. Teller, R. Rasmussen, I. Geresdi, Z. Pan, and X. Liu, 2012: Effects of aerosol solubility and regeneration on mixedphase orographic clouds and precipitation. J. Atmos. Sci., 69, 1994-2010, doi:10.1175/JAS-D-11-098.1.

Zelinka, M., and D. L. Hartmann, 2009: Response of humidity and clouds to tropical deep convection. J. Climate, 22, 2389-2404, doi:10.1175/2008JCLI2452.1. 